\begin{tabular}{|l|l|}
\hline RI & 8282 \\
\hline
\end{tabular}

Bureau of Mines Report of Investigations/1978

Design Requirements for Uranium Ion Exchange From Acidic Solutions in a Fluidized System 


\section{DISCLAIMER}

This report was prepared as an account of work sponsored by an agency of the United States Government. Neither the United States Government nor any agency Thereof, nor any of their employees, makes any warranty, express or implied, or assumes any legal liability or responsibility for the accuracy, completeness, or usefulness of any information, apparatus, product, or process disclosed, or represents that its use would not infringe privately owned rights. Reference herein to any specific commercial product, process, or service by trade name, trademark, manufacturer, or otherwise does not necessarily constitute or imply its endorsement, recommendation, or favoring by the United States Government or any agency thereof. The views and opinions of authors expressed herein do not necessarily state or reflect those of the United States Government or any agency thereof. 


\section{DISCLAIMER}

Portions of this document may be illegible in electronic image products. Images are produced from the best available original document. 
Report of Investigations 8282

\section{Design Requirements for Uranium Ion Exchange From Acidic Solutions in a Fluidized System}

By D. E. Traut, I. L. Nichols, and D. C. Seidel

This report was prepared as an aceount of work
sponsored by the United States Government Netther the
United States nor the United States Department of
Energy, nor any of their employees, nor any of their
contractors, subcontractors, or their employees, makes
any warranty, express or implied, or assumes any legal
lability or responsibilty for the accuracy, completeness
or use fulness of any information, apparatus, product or
process disclosed, or represents that its use would not
infringe privately owned nghts

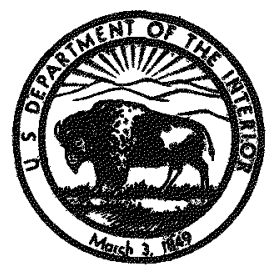

UNITED STATES DEPARTMENT OF THE INTERIOR Cecil D. Andrus, Secretary

BUREAU OF MINES 
This publication has been cataloged as follows:

\section{Traut, Davis E}

Design requirements for uranium ion exchange from acidic solutions in a fluidized system / by D. E. Traut, I. L. Nichols, and D. C. Seidel. [Washington]: U.S. Dept. of the Interior, Bureau of Mines, 1978.

29 p. : ill., diagrams; $27 \mathrm{~cm}$. (Report of investigations - Bureau of Mines ; 8282)

Bibliography: p. 29.

1. Uranium. 2. Leaching. 3, Ion exchange. I. Nichols, Ivan L., joint author, II. Seidel, Don Cv, joint author. Im. United States. Bureau of Mines. IV. Title. V. Series: United States. Bureau of Mines. Report of investigations - Bureau of Mines ; 8282.
TN23.U7
no. 8282
622.06173

U.S. Dept, of the Int * Library 


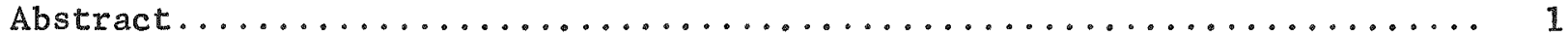

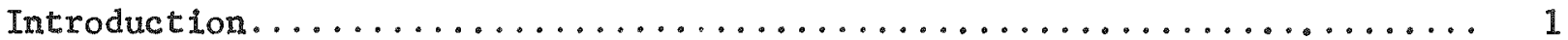

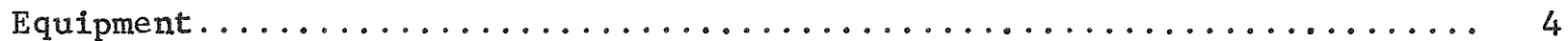

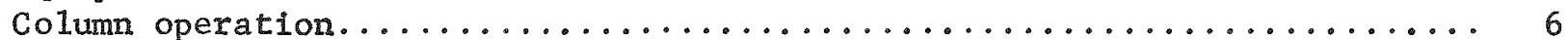

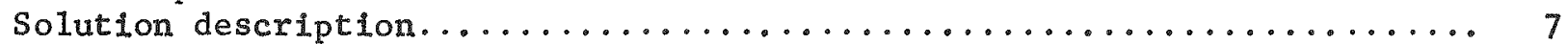

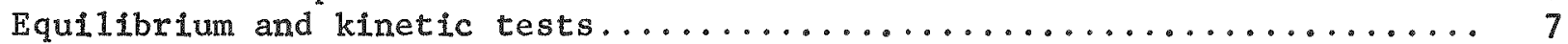

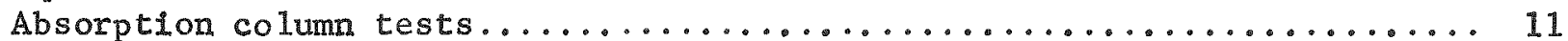

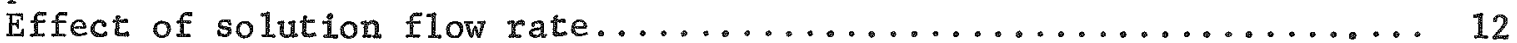

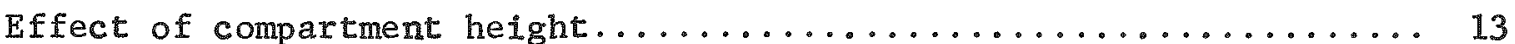

Effect of amount of resin withdrawa $1 \ldots \ldots \ldots \ldots \ldots \ldots \ldots \ldots \ldots$

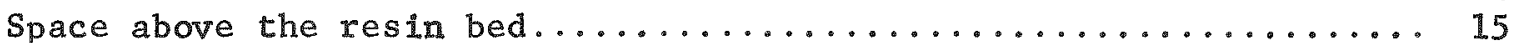

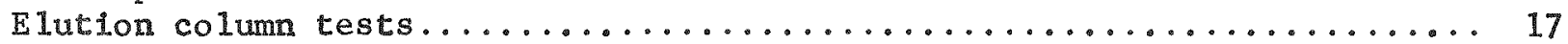

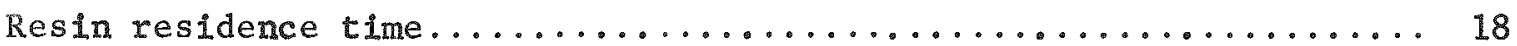

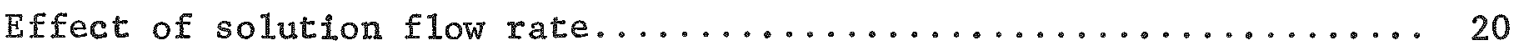

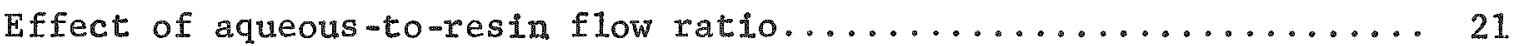

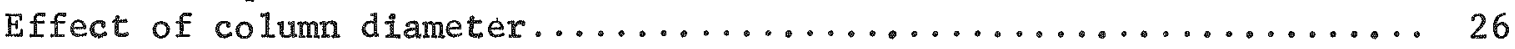

Effect of compartment height $\ldots \ldots \ldots \ldots \ldots \ldots \ldots \ldots \ldots \ldots \ldots \ldots \ldots \ldots \ldots \ldots \ldots \ldots \ldots \ldots \ldots \ldots \ldots \ldots$
summary $\ldots \ldots \ldots \ldots \ldots \ldots \ldots \ldots \ldots \ldots \ldots$

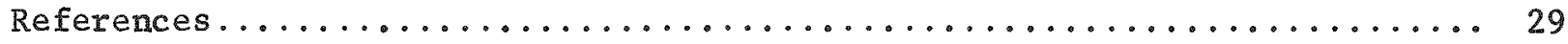

\section{ILLUSTRATIONS}

1. Multiple-compartment, ion-exchange column................. 3

2. Overa11 view of the two-multiple-compartment-columns system....... 4

3. Flowsheet of the MCIX-columns system..................... 5

4. Sequence of resin withdrawal cycle from MCIX absorption column..... 6

5. Absorption equilibrium isotherm between uranium solution and

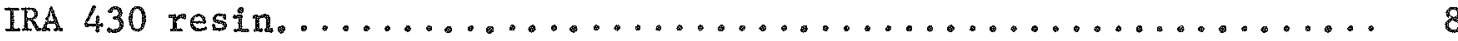

6. Contact pyramid for resin and solution to obtain an equilibrium

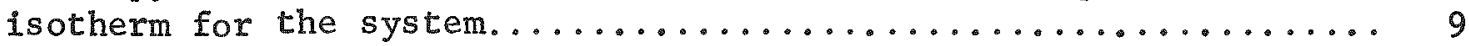

7. Equilibrium isotherm for elution with $1.5-\mathrm{M} \mathrm{NaC} 1$ from IRA 430 resin. 10

8. Kinetic data on sodium chloride elution of IRA 430 resin.......... 11

9. Effect of solution flow rate on uranium absorption from solution.... 12

10. Effects of 1 -foot and 2-foot compartment heights on absorption...... 14

11. Effect of partial-compartment resin withdrawal on absorption...... 15

12. Effect of solution flow rate on the space above the resin bed...... 16

13. Replication of elution column results..................... 18

14. Effect of resin residence time on elution efficiency............ 19

15. Effect of solution flow rate on elution efflciency (1-inch-ID colum, 1-foot compartments, aqueous-to-resin ratio of $10: 1$ ) .... 20

16. Effect of solution flow rate on elution efficiency (2-inch-ID column, 1-foot compartments, aqueous-to-resin ratio of $10: 1) \ldots 21$

17. Effect of solution flow rate on elution efficiency $(2$-inch-ID column, 1-foot compartments, aqueous-to-resin ratio of $6: 1$ ).....

18. Effect of solution flow rate on elution efficiency $(2-$ inch-ID column, 2-foot compartments, aqueous-to-resin ratio of $10: 1) \ldots$

19. Effect of aqueous-to-resin flow ratio on elution efficiency ( 1 -inchID column, 1-foot compartments, solution flow rate of $2.7 \mathrm{gpm} / \mathrm{ft}^{2}$ ) 
20. Effect of aqueous-to-resin flow ratio on elution efficiency (2-inch-

ID column, 1-foot compartments, solution flow rate of $\left.2.7 \mathrm{gpm} / \mathrm{ft}^{2}\right) 24$

21. Effect of aqueous-to-resin flow ratio on elution efficiency (2-inch-

ID column, 1-foot compartments, solution flow rate of $4.0 \mathrm{gpm} / \mathrm{ft}^{2}$ ) 25

22. Effect of aqueous-to-resin flow ratio on elution efficiency $(2-i n c h-$

ID column, 2-foot compartments, solution flow rate of $\left.2.7 \mathrm{gpm} / \mathrm{ft}^{2}\right) 25$

23. Effect of column diameter on elution efficiency.............. 26

24. Effect of compartment height on elution efficiency............ 27

TABLE

1. Effect of resin residence time on elution................. 19 


\title{
DESIGN REQUIREMENTS FOR URANIUM ION EXCHANGE FROM ACIDIC SOLUTIONS IN A FLUIDIZED SYSTEM
}

by

D. E. Traut, ${ }^{1}$ I. L. Nichols, ${ }^{2}$ and D. C. Seidel ${ }^{3}$

\begin{abstract}
A fluidized, countercurrent ion-exchange system was developed, operated, and evaluated by the Bureau of Mines in support of its objective to help assure an adequate uranium supply for future national needs. The system consisted of integrated multiple-compartment absorption and elution column in which the solution flows are continuous, except for short periods when resin increments are withdrawn. The exchange of uranyl sulfate between a simulated acid-leach-uranium solution and a strong-base, lon-exchange resin was studied, together with subsequent elution using an acidified sodium chloride solution. The effects of the number of compartments, compartment height, amount of resin withdrawal, solution flow rate, and column diameter were investigated. Also examined were the kinetic and equilibrium relationships for the absorption and elution steps. The experimental data indicate a strong interdependence between variables. Solution retention time appears to be a major limiting variable in the absorption process, while resin residence time is the determining factor in the elution process. The columns system was efficient over a range of conditions, but close control was needed for optimum operation.
\end{abstract}

\section{INTRODUCTION}

Present Bureau of Mines uranium research is predicated on projections that requirements for uranium will increase fourfold to sixfold during the next two decades, and development of lower grade resources will be necessary to augment presently known reserves. Present production is generally from ores containing 0.1 to 0.3 percent $U_{3} O_{8}$, but future production is expected to be from ores containing 0.03 to 0.1 percent $\mathrm{U}_{3} \mathrm{O}_{8}$. Also, because uranium operations encounter increasing amounts of refractory carboniferous and siliceous

\footnotetext{
${ }^{1}$ Chemical engineer, Salt Lake City Metallurgy Research Center, Bureau of Mines, Salt Lake City, Utah (now with Boulder City Metallurgy Engineering Laboratory, Bureau of Mines, Boulder City, Nev.).

${ }^{2}$ Metallurgist, Salt Lake City Metallurgy Research Center, Bureau of Mines, Sa1t Lake City, Utah.

${ }^{3}$ Research supervisor, Salt Lake City Metallurgy Research Center, Bureau of Mines, Salt Lake City, Utah.
} 
materials, new or modified process technology is required to improve the uranium recovery from such ores.

An objective of the present work is to help assure an adequate supply of uranium fuel to meet the projected demand for nuclear energy by making technological improvements in the processes for extracting uranium from ores and low-grade uraniferous materials. Research is directed toward new and improved metallurgical processes including hydrometallurgical methods. Part of the research is concerned with development of ion-exchange extraction procedures for recovering uranium at less cost and in the form of a high-grade product from solutions and slurries.

Ion exchange has been used to recover uranium from acidic leach solutions since the early 1950's. The uranium-bearing leach liquor is contacted with an anionic resin, and the uranium exchanges as an anionic uranium sulfate complex. This complex is then eluted from the resin by displacing the uranium complex with another anion, such as $\mathrm{Cl}^{-}, \mathrm{SO}_{4}{ }^{=}$, or $\mathrm{NO}_{3}{ }^{-}$. The uranium is recovered from the eluate by various precipitation techniques; the final uranium mil1 product is designated as "yellow cake." This material is normally shipped to other operations for further refining.

A variety of Ion-exchange systems have been used. Most of these systems have been described by Merritt (3). Each of the systems has both advantages and limitations; for example, some systems can handle only clarified feed solutions, while other systems require relatively large resin inventories and higher capital investments. During research by the Bureau of Mines on recovery of uranium from dilute mine waters, a new, low-cost system of lon exchange was developed that is applicable to clear solutions and many slime slurries (1. 5-7). The primary component of this system has been designated as the multiple-compartment, ion-exchange (MCIX) column (fig. 1), in which the upflowing feed solution fluidizes the ion-exchange resin in a series of compartments. The compartments are separated by orifice plates; the orifice openings constitute about 5 percent of the columncross-sectional area. The feed solutions flow upward at rates of about 10 to $20 \mathrm{gpm} / \mathrm{ft}^{2}$. This fluidizes the resin in each compartment, but the upward flow through the orifices prevents the resin from dropping into a lower compartment. Periodically, the feed stream is momentarily interrupted, at which time a discharge valve is opened and an increment of resin is discharged. This operational cycle permits the increments of resin to move down through the column countercurrent to the solution flow. A similar column arrangement can also be used for elution of the loaded resin.

A 14-inch-ID, MCIX absorption column and a 4-inch-ID, fixed-bed, upflow elution column were field tested on uranium-bearing mine water at Bingham Canyon, Utah, and Grants, N. Mex. The same system was tested on alkaline leach slurry at Moab, Utah. A 6-foot-ID column was hydraulically tested in Salt Lake City, Utah (1, 5, 7). A 20-inch-ID absorption column was tested on acid leach slurry at Edgement, S. Dak. Laboratory testing with a 2-inch-ID

Underlined numbers in parentheses refer to items in the 1ist of references at the end of this report. 


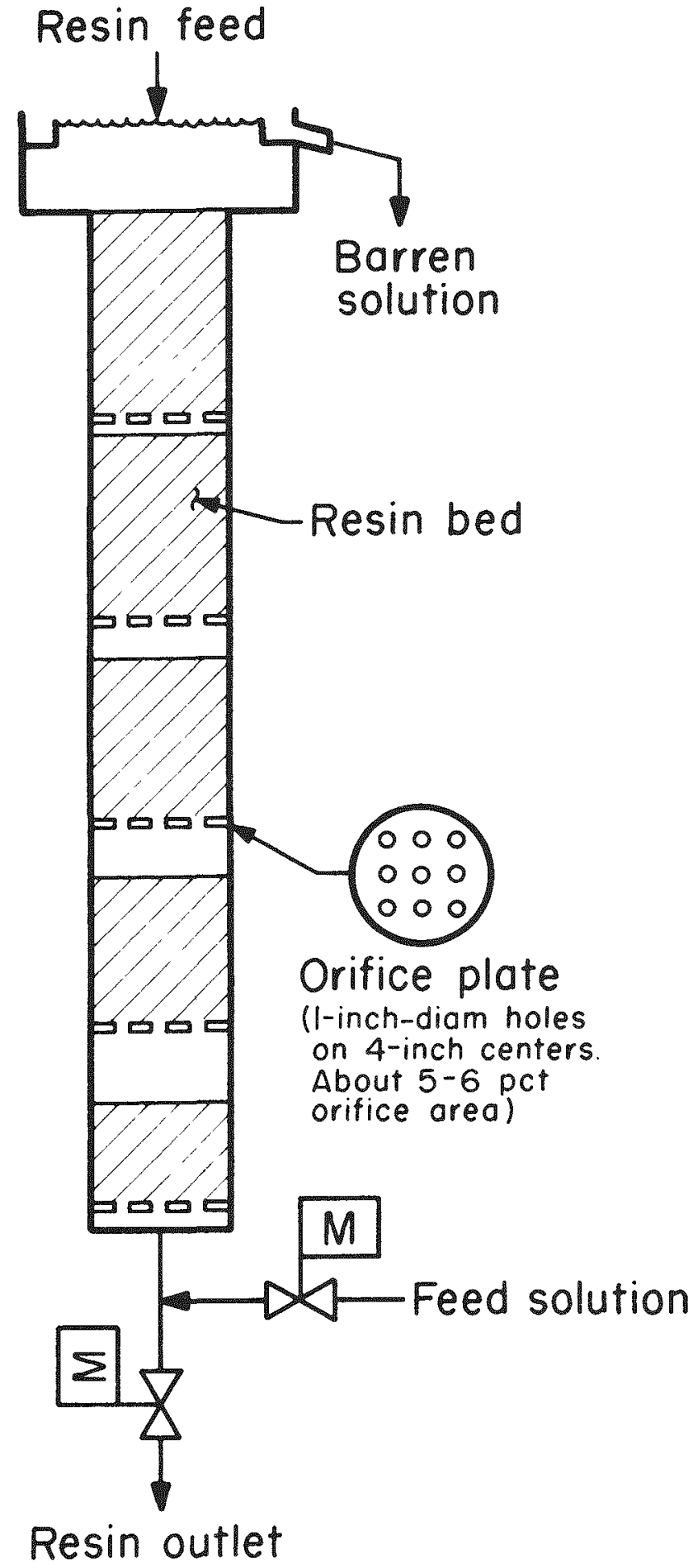

FIGURE 1. Multiple-compartment, ionexchange column. column showed that is was feasible to use a compartmented column for countercurrent elution (6).

Previous cost estimates indicated considerable savings over conventional resin-in-pulp (RIP), basket-type operations because the resin requirement for the compartmented columns was determined to be about 35 percent of the amount needed by basket-type, RIP circuits of the same throughput capacity (6). Based on 1972 costs and a throughput leve 1 of 2,000 tons of ore per day, it was determined that the capital required for a hypothetical ionexchange plant using MCIX columns would be 73 percent of that needed for a solvent-extraction plant; the operating costs for the ion-exchange plant would be 81 percent of that for the solvent extraction plant (6).

MC IX columns are commercially used to recover gold from cyanide solutions using coarse, activatedcarbon particles (4), and prototype columns are in use for uranium absorption and elution.

During the past 3 years, the Bureau has conducted additional studies to better quantify the design criteria for multiplecompartment, ion-exchange columns. The investigations discussed in this report involve the use of 1-, 2-, and 4-inch-ID columns. These columns are improved modifications of earlier designs; more precise flow contro1 and sequential-timing instrumentation were added to obtain better reproducibility and operational continuity. Both individua 1 and integrated absorption-elution circuit arrangements were used during this work. 


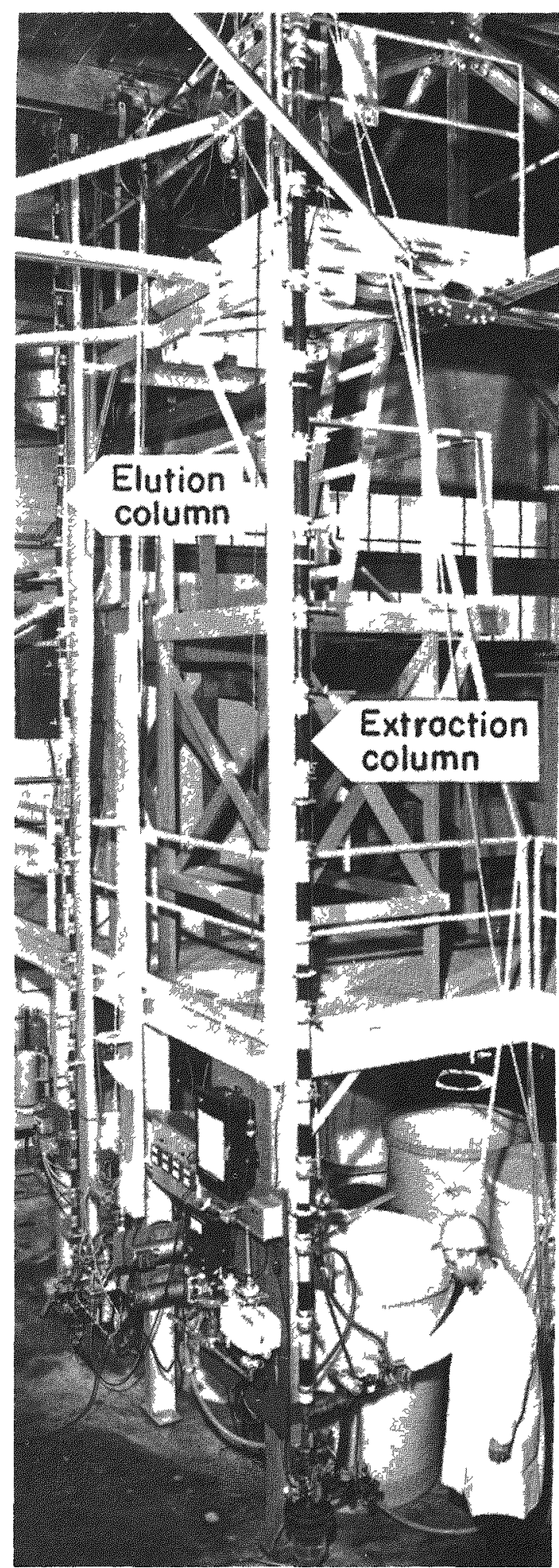

FIGURE 2.- Overall view of the two-multiple-compartment-columns system.

\section{EQUIPMENT}

The main component of the absorption equipment used in the current experimental program was a 2-inch-ID by 16-foot-high glass column composed of 1-foot sections as shown in figure 2. Three different sizes of glass elution columns were tested: (1) 1 inch ID by 22 feet high; (2) 2 inches ID by 16 feet high; and (3) 4 inches ID by 17 feet high. The 1-inch-ID column was composed of 6-inch sections, while the 2-inch-ID and 4-inch-ID columns were composed of 1-foot sections. A detailed flowsheet of the columns system is shown in figure 3. Individual compartments were separated by orifice plates that had openings equivalent to approximately 6 percent of the column cross-sectional area. The columns were constructed so that compartment height could be modified by substituting full-dianeter couplings for the orifice-plate couplings. Rosenbaum and Ross state the following about the use of these orifice plates ( $\underline{6})$ :

Observation has shown that when a regulated flow of solution passes upward through a column of closely sized resin at a rate sufficient to fluidize the resin, vertical mixing occurs over the length of the column. In effect, the entire column serves as a gently agitated reactòr and, under these conditions, equilibrium string ently limits the absorption kinetics and efficiency. By assembling the resin column out of short segments, each separated by a perforated plate, vertical mixing still occurs within each segment of expanded-bed resin, but the net overall effect is of multiple-stage absorption or elution yielding more rapid and complete ion transfer than obtainable in a noncompartmented column of equivalent height. 
Under ideal operating conditions, each compartment is nearly full of fluidized resin in equilibrium with the upflowing solution. If the quantity of resin in any compartment is initially in excess of the equilibrium volume, the excess resin moves up through the perforated plate into the next compartment. If the quantity of resin is less than the equilibrium volume, the compartment will not be completely filled. Downward movement of resin between compartments can occur only when the velocity of the solution flow through the holes in the perforated plates is less than the terminal settling velocity of the resin particles. An increase in solution flow rate or density will cause the resin bed to expand. When using coarse bed resins, minus 16-plus 20-mesh, perforated plates that have an open area of approximately 5 percent are satisfactory.

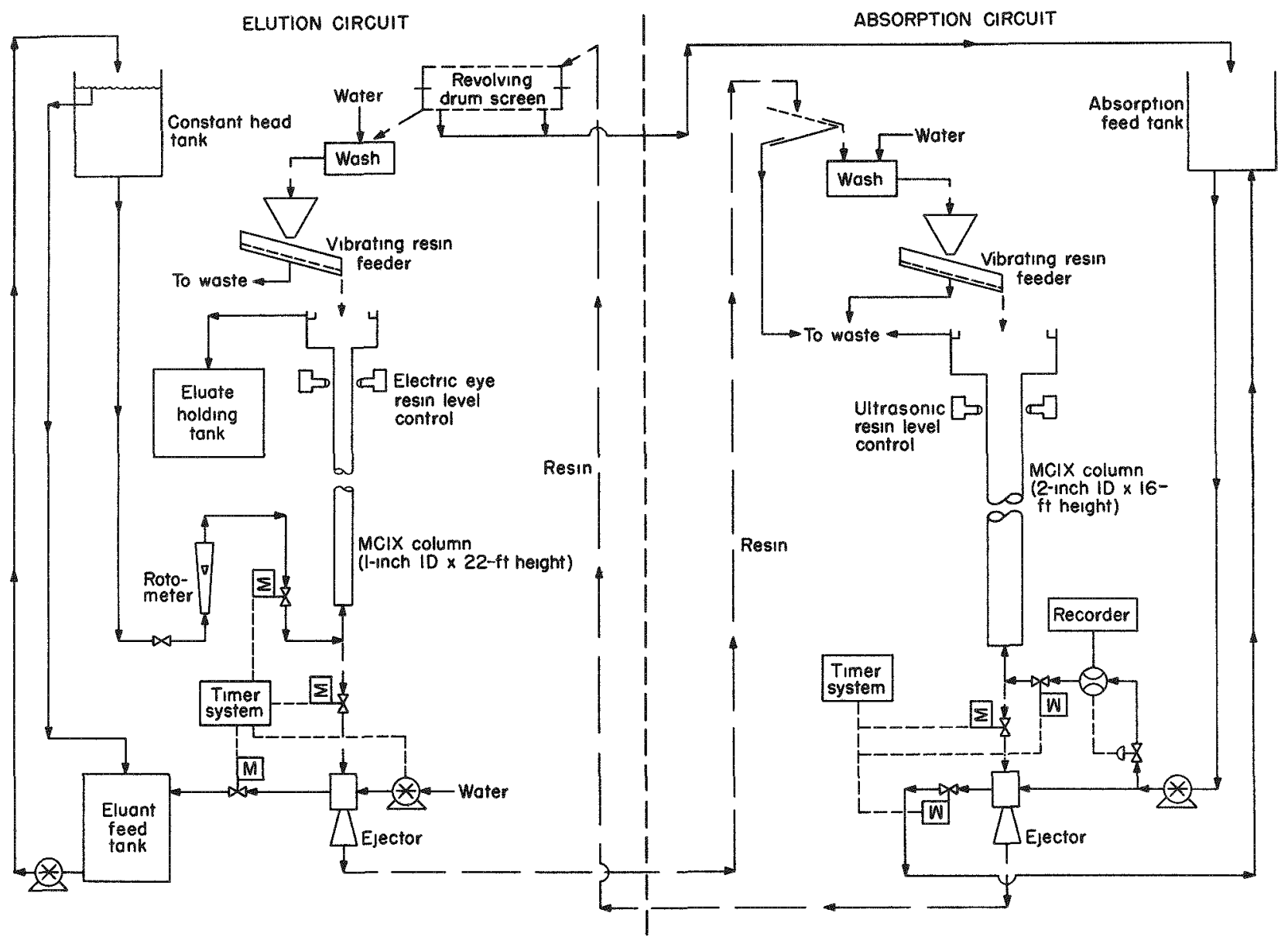

FIGURE 3. - Flowsheet of the MCIX-columns system. 


\section{COLUMN OPERATION}

The column is operated with a continuous upflow of solution except for scheduled resin withdrawals. During these resin withdrawals, the automatic solution-inlet valve closes and the automatic resin-outlet valve opens to discharge a programed amount of resin from the column. The discharge periods are approximately 6 to 12 seconds for the absorption column 3 to 6 seconds for the 1-inch-ID elution column, and 6 to 12 seconds for the 2-1nch-ID and 4-inch-ID elution columns. The time interval between withdrawals from the absorption column is determined by the amount of resin to be discharged per withdrawal cycle, which is a function of feed-solution flow rate,

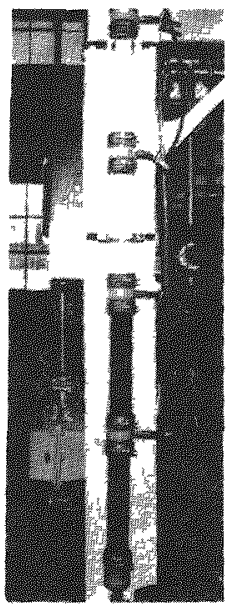

O second

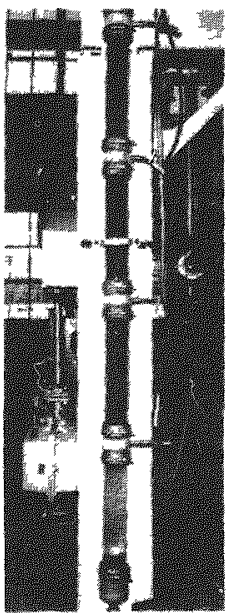

9 seconds

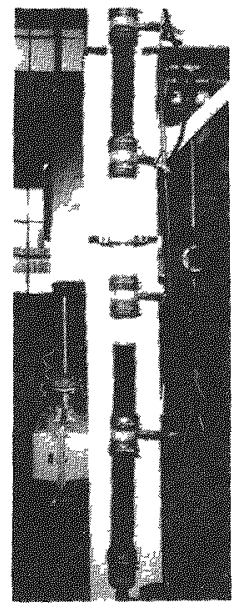

2 seconds

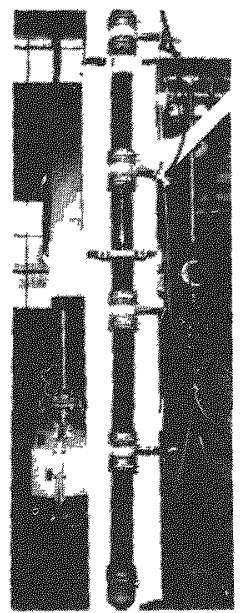

20 seconds

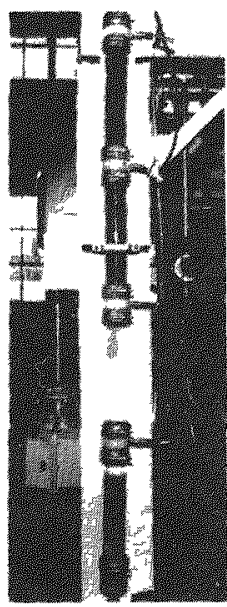

7 seconds

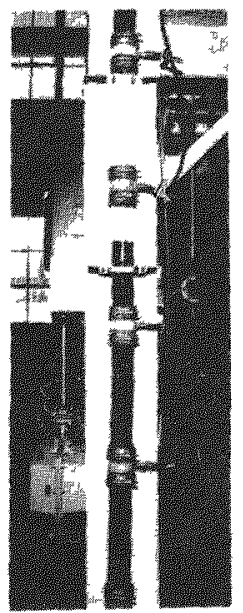

60 seconds

RESIN WITHDRAWAL CYCLE

O second-pesin bed at steady state level.

9 seconds-end of withdrawal.

60 seconds-resin bed approaching steady state level.

FIGURE 4. - Sequence of resin withdrawal cycle from MCIX absorption column. 
feed-solution concentration, and desired resin loading. Similarly, for the elution column, the amount of resin discharged per cycle is a function of feed-resinconcentration, eluant flow rate, desired resin elution, and desired eluate grade. The actual time during which the resin-discharge valve must be open to discharge a programed amount of resin is a function of the valveopening configuration and the bed expansion. During column operation, the solution flows were controlled by automatic instruments, and the open time interval on the resin-discharge valve was set by trial-and-error adjustments. Figure 4 shows a pictorial sequence for one cycle of the resin-discharge operation. The 4-foot compartment shown in this figure is composed of 1 -foot glass sections and full-diameter couplings.

Controllers of the solution flow rate are a critical component of the system. Previous work did not have the precise flow rate control necessary to assure steady-state operation. Without this contro1, the resin migrates from one compartment to another at random, and the column conditions remain transient. To control solution flow to the 2 - and 4 -inch-ID colums, an automatic system was used, which consisted of a magnetic flowmeter, a controller, and an air-diaphragm valve. This system was precise to within \pm 1 percent of the maximum flow rate through the magnetic flowmeter. To control the relatively low flow rates to the 1-inch-ID column, a constant head tank and rotameter were used. Absorption and the subsequent elution were conducted at room temperature.

\section{SOLUTION DESCRIPTION}

The absorption-column feed solution used for these tests simulated the composition of a uranium-leach liquor typical of that in a Wyoming mil that processes Shirley Basin ore. Chemical analysis of this clear, simulated, mill solution follows, in grams per liter:

\begin{tabular}{|c|c|c|c|}
\hline $\mathrm{U}_{3} \mathrm{O}_{8} \ldots \ldots$ & 0.92 & $C 1 \ldots \ldots \ldots$ & 0.20 \\
\hline $\mathrm{Mg} . . .$. & .26 & $A 1 \ldots \ldots$ & .21 \\
\hline $\mathrm{Fe} \ldots$ & .23 & $\mathrm{Ca}$. & .51 \\
\hline Mn... & .60 & $\mathrm{SO}_{4} \ldots$ & 8.07 \\
\hline $\mathrm{Na} \ldots \ldots \ldots$ & .28 & $\mathrm{pH} . \ldots \ldots \ldots$ & 2.0 \\
\hline
\end{tabular}

EQUILIBRIUM AND KINETIC TESTS

Laboratory tests were conducted to collect uranium-equilibrium data during absorption and elution of a strong-base anion resin. Kinetic data were determined for the elution step. This information was useful in columnoperation predictions and evaluations.

The equilibrium isotherm for the absorption feed solution and resin (Amberlite IRA $430^{5}$ ) is shown in figure 5. This isotherm was obtained by a

5Reference to specific trade names or manufacturers does not imply endorsement by the Bureau of Mines. 


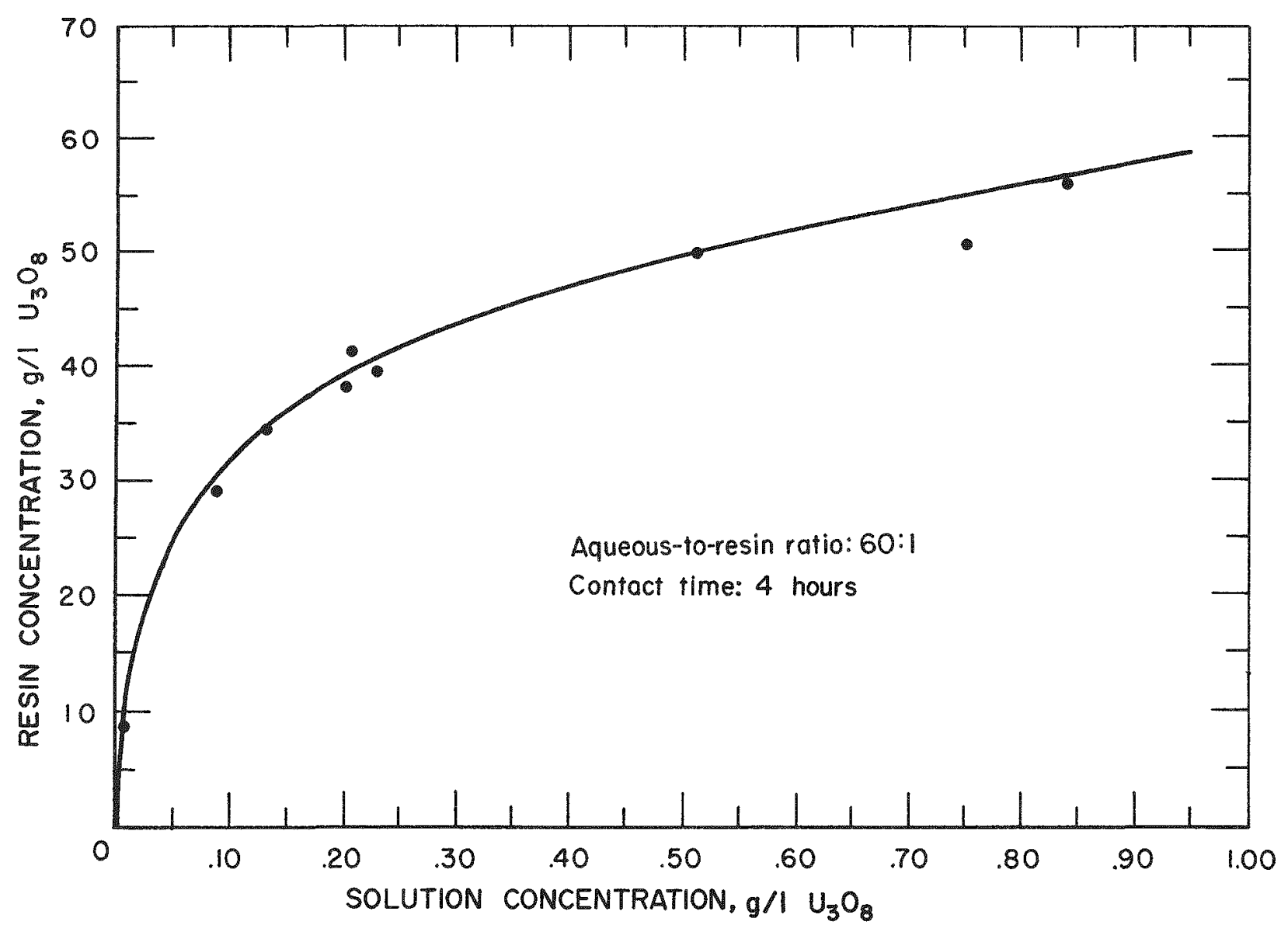

FIGURE 5. - Absorption equilibrium isotherm between uranium solution and IRA 430 resin.

pyramidal schedule of contacts as shown in figure 6 . This method is a series of crosscurrent batch contacts between the solution and resin (8). The aqueous-to-resin ratio was $60: 1$ and a contact time of 4 hours was considered to be equivalent to an infinite time. 
Steps

1

2

3

4

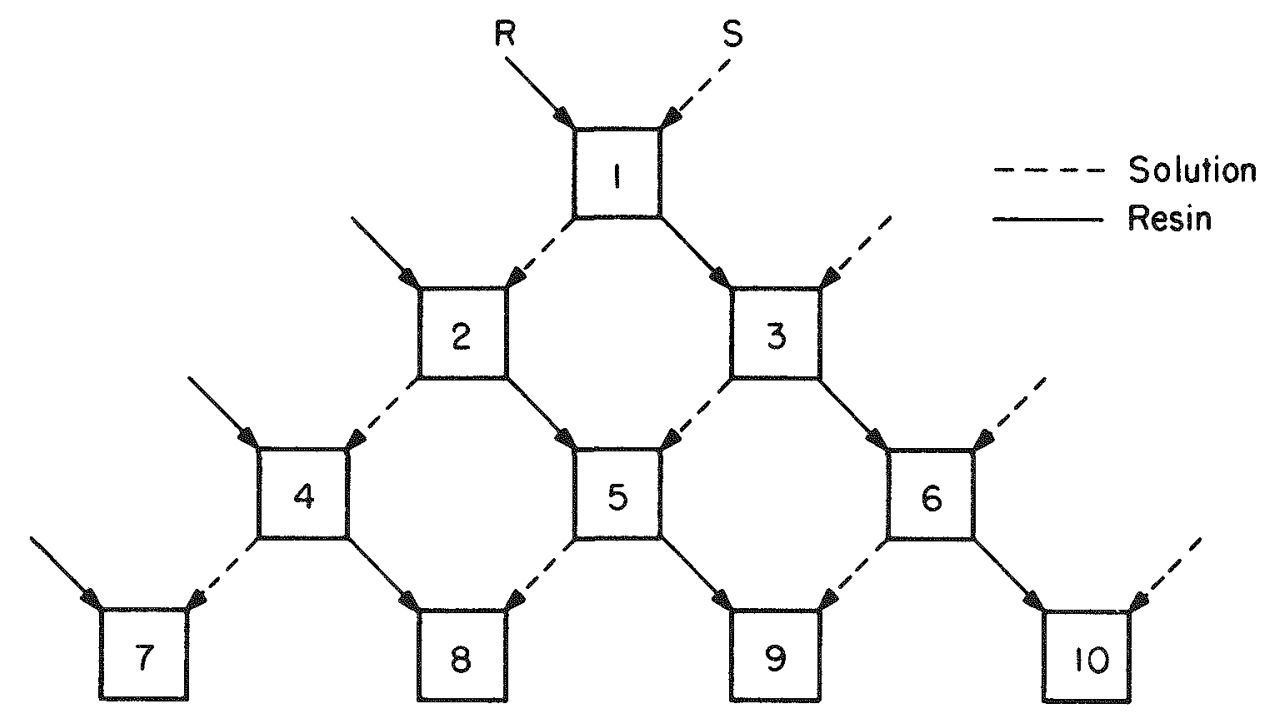

5
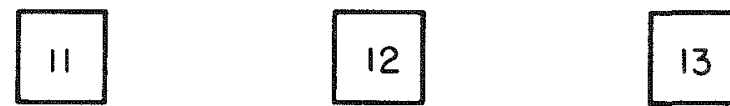

14

15

6
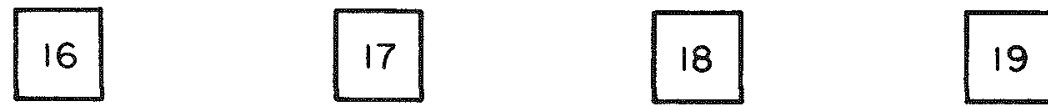

20

21

722

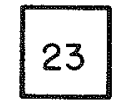

24

25

26

27

FIGURE 6. - Contact pyramid for resin and solution to obtain an equilibrium isotherm for the system. 
The equilibrium isotherm for the eluant and IRA 430 is shown in figure 7. This isotherm was obtained by the same procedure as described above for the absorption feed solution except that an aqueous-to-resin ratio of $4: 1$ was used. The eluant was a $1.5-\mathrm{M}$ NaCl solution acidified to $\mathrm{pH} 1.0$ with $\mathrm{H}_{2} \mathrm{SO}_{4}$. The kinetic relationship for the elution system (fig. 8) shows the initial elution exchange as a function of time. These data were obtained by contacting the eluant and resin batchwise in a stirred reactor and withdrawing solution samples at predetermined times.

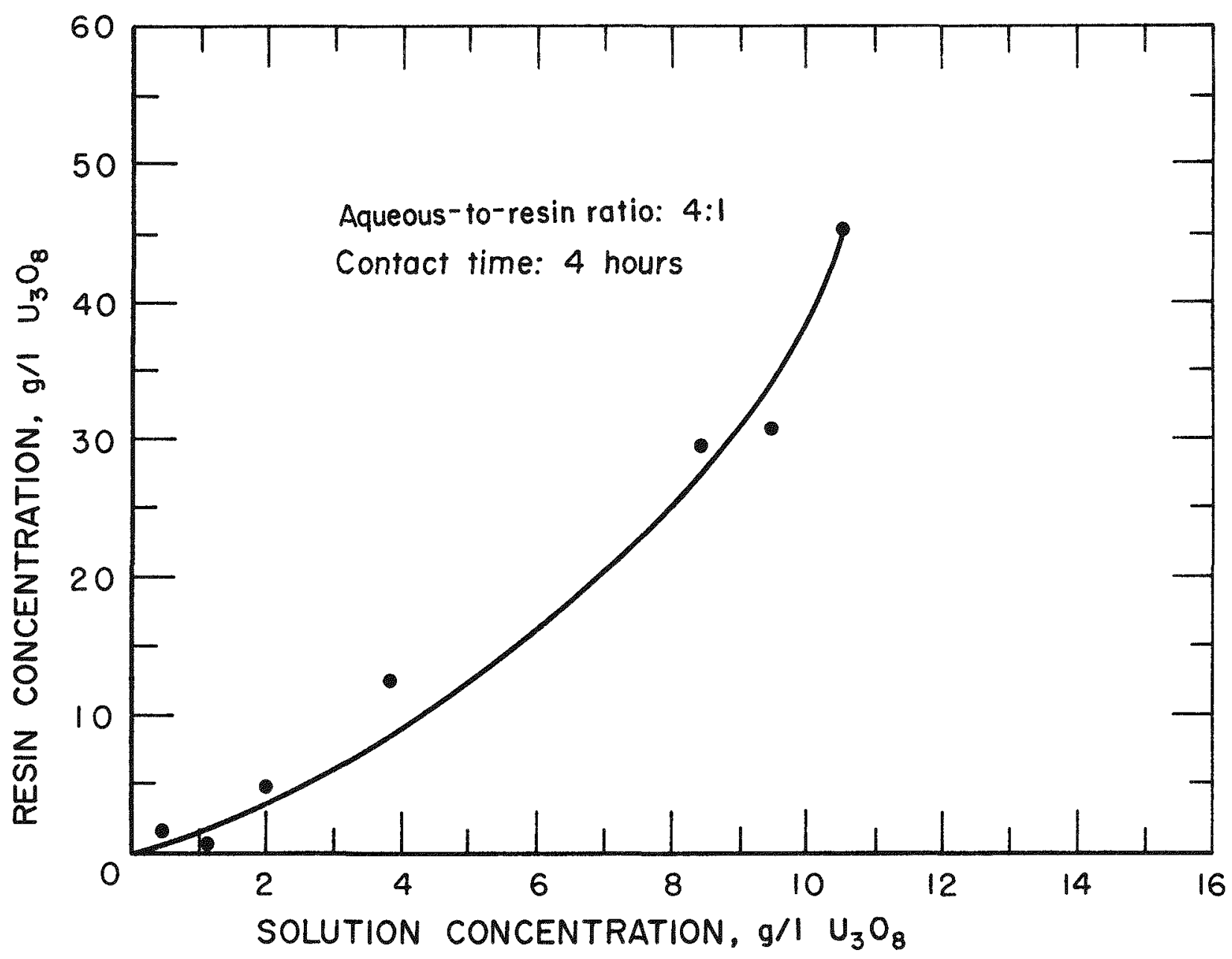

FIGURE 7. - Equilibrium isotherm for elution with 1.5-M NaCl from IRA 430 resin. 


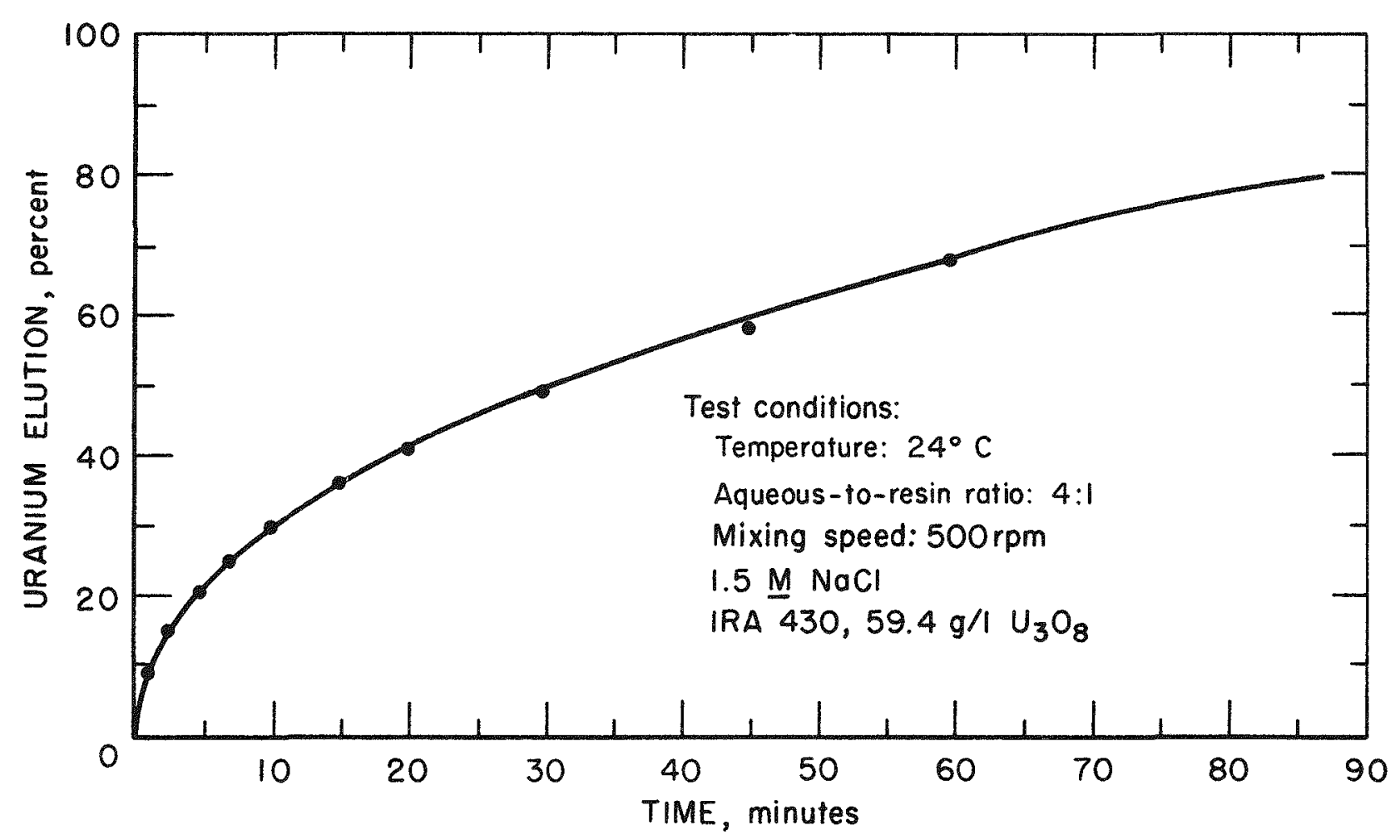

FIGURE 8. - Kinetic data on sodium chloride elution of IRA 430 resin.

\section{ABSORPTION COLUMN TESTS}

Operating characteristics of the countercurrent 2-inch-ID absorption column were determined using a coarse-bead (approximately 16- by 20-mesh), strong-base, anion resin (Amberlite IRA 430) with the synthetic mill solution previously described. The orifice plates were perforated with one centered 29/64-inch hole per plate, and the column was divided by these plates into sections of equal height; section heights were varied for the different tests. The column was fitted with motorized valves actuated by electric timers to control the on-off flows of the solution and resin. Precision control of the solution flow rate was obtained with an automatic air-diaphragm valve coupled to a magnetic flowmeter control system.

The following characteristics of the absorption column were studied:

1. Solution flow rate.

2. Compartment height.

3. Amount of resin withdrawa1.

4. Space above the resin bed. 


\section{Effect of Solution Flow Rate}

The optimum economic solution flow rate per unit area of column diameter is a major consideration when designing a column system. The limiting maximum flow rate is the rate that will carry resin from the top of the column. The minimum solution flow rate to the column is determined by the resin fluidization required for mechanical transfer of the resin during the withdrawal

cycle. However, as the flow rate increases above this minimum, the solution residence time per foot of column height decreases, and a taller column may be required. Optimum economic design would require compromises among the four parameters of column diameter, column height, solution flow rate, and uranium recovery.

The effect of solution flow rate is illustrated in figure 9, which shows the solution-extraction-column profile for four solution flow rates through 1-foot compartments. As the solution flow rate increases, more of the column is utilized to obtain the same amount of uranium extraction from the solution. This can be attributed to residence time; that is, the solution must be in

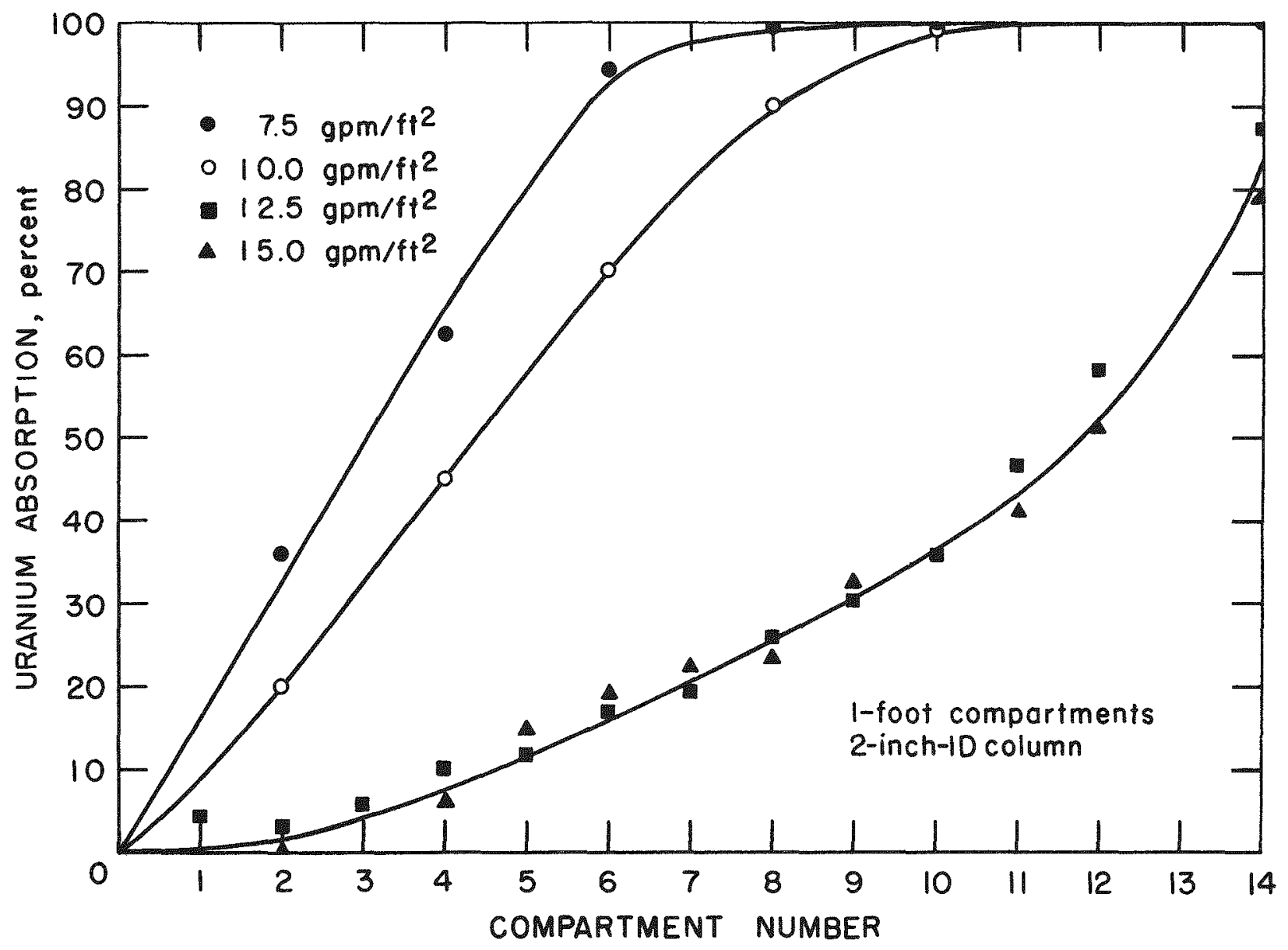

FIGURE 9. - Effect of solution flow rate on uranium absorption from solution. 
contact with resin for a certain minimum time, and with higher solution flow rates, this time requirement forces the extraction to take place in a higher compartment. Therefore, for a colum height similar to the one tested (16 feet composed of 1 -foot compartments), a solution flow rate of about 10 $\mathrm{gpm} / \mathrm{ft}^{2}$ appears optimum for a feed solution containing about $1 \mathrm{~g} / 1 \mathrm{U}_{3} \mathrm{O}_{8}$.

\section{Effect of Compartment Height}

The multiple-compartment column can be considered as an assemblage of agitated stages in which extraction is achieved by a series of mass transfers from the solution to the resin. To be effective, the column must provide the required number of transfer stages, each having sufficient solution residence time for a reasonable approach to equilibrium mass transfer. As discussed in the previous sections, the solution retention time is critical because the transfer of uranium from the solution to the resin sites is not instantaneous. The stage height is of particular consequence because it can affect both the column construction cost and the inventory of resin required to fill the column.

Studies have been made to determine the effect of compartment height on column efflciency. Figure 10 illustrates the uranium-extraction profile of the 2-inch-ID absorption column when operating with 1-foot compartments and with 2 -foot compartments. The solution flow rate was $10 \mathrm{gpm} / \mathrm{ft}^{2}$, and the solution-to-resin throughput ratio was approximate1y 6:1. These curves indicate that the mass transfer of uranium per foot of column height was essentially the same for both the 1 -foot and 2-foot compartment heights. It was concluded that there was a compromise between the effects of solution residence time per stage and the number of stages in the total column.

Tests were also made using 4-foot compartment heights, but observations and indirect evaluations indicated that the degree of mixing in the 4-foot height was significantly less than that in the 1-foot and 2-foot compartments. This change was probably the result of the increased wall effects produced by the 4 -foot compartments. The resin classified in these relatively long, narrow compartments, and a favorable chromatographic loading effect was obtained. This effect produced loadings that were significantly greater than the theoretical loading that can be obtained in a mixed stage. Subsequent observations of the mixing in a resin bed 6 inches in diameter by 4 feet deep indicated that the up-and-down movement of resin in this column was considerably greater than in the 2-inch-ID column. This inconsistent mixing in the 2-inch-ID column precludes comparison of data from the 4-foot compartments with those from the 1-foot and 2-foot compartments.

It is possible that favorable resin classification may take place in larger diameter columns, but additional tests will be required to determine the degree of classification, if any.

In general, the current data indicate that compartment heights of about 1 foot to 2 feet will produce approximately the same absorption efficiency for a given column height. It is also possible that this uniform efficiency may extend to 4-foot compartment heights. 


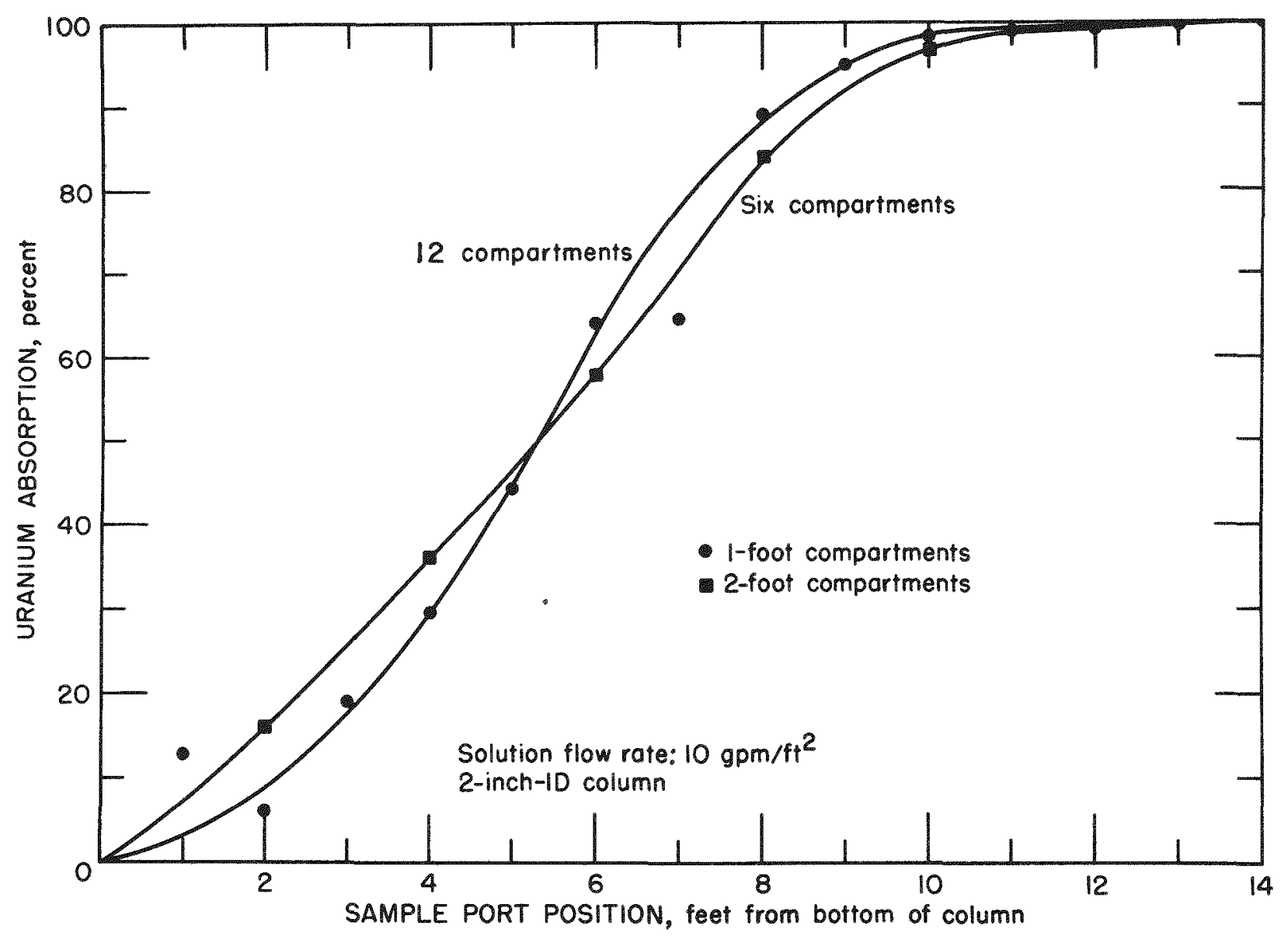

FIGURE 10. - Effects of 1-foot and 2-foot compartment heights on absorption.

\section{Effect of Amount of Resin Withdrawa1}

For the 2-inch-ID column used in these tests, the withdrawal of a fu11 compartment of resin could be completed within a short interval of 3 to 15 seconds. It was possible, therefore, to withdraw any desired fraction of the resin from one compartment with a minimum of handiing problems and interruption of column feed. However, in a large column where the resin in one compartment constitutes a substantial volume, the withdrawal and, more particularly, the screening, washing, and transferring of resin from an entire compartment would present mechanical handling difficulties. An operational cycle with partial withdrawal would minimize this difficulty. Tests were run to evaluate the effect of such partial-section withdrawal. Since the resin becomes more dense as it is loaded with uranium, the upward flow of solution tends to classify the more heavily loaded resin beads at the bottom of each section. Therefore, in half-section withdrawals, the heaviest resin is always withdrawn. A1so, as the heavy resin moved downward, the smaller resin chips and beads tend to accumulate in the top of the column. The comparison of column profiles for a full-section resin withdrawal and a half-section withdrawal is shown in figure 11 . 


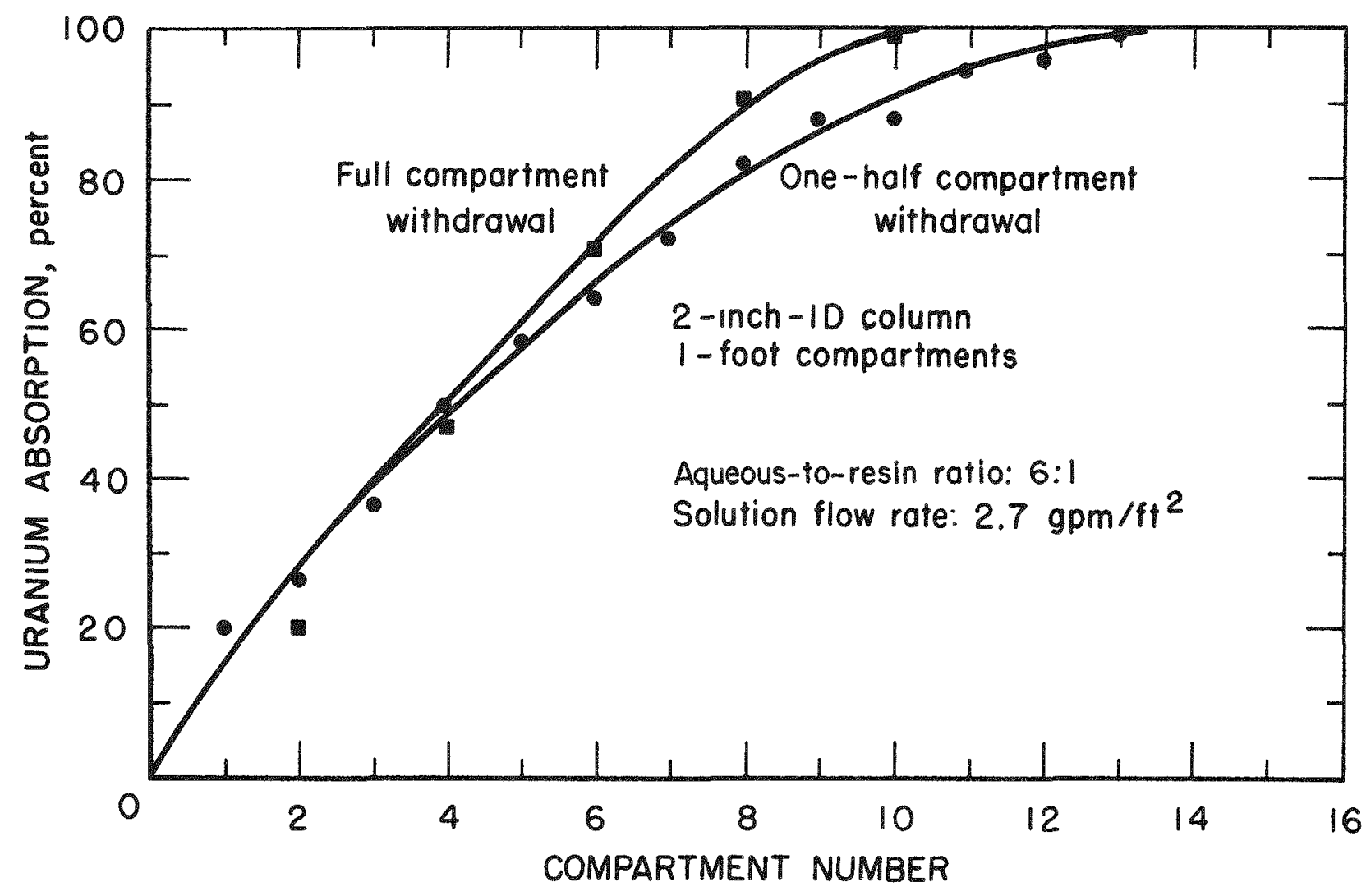

FIGURE 11. - Effect of partial-compartment resin withdrawal on absorption.

The data show a significant difference in the efficiency of the two methods of resin withdrawa1; this difference is most evident in the top sections of the columns. Using the half-section withdrawal, mechanical transfer constraints develop, which limits the amount of resin in the column. As a result, a longer column is required to obtain comparable absorption of the uranium from the feed solution. Thus it is concluded that full-section withdrawals would permit the most efficient utilization of column height.

\section{Space Above the Resin Bed}

During the normal operation of the absorption column, eluted resin is fed into the top compartment of the absorption column and the resin level is maintained by an automatic controller. The eluted resin is the lightest resin in the column and, therefore, the resin bed in this top compartment is the most expanded bed in the column. As a resin increment is withdrawn from the bottom of the column, the resin in the rest of the column compartments moves down. When steady-state operation has been achieved, only a fixed amount of resin is transferred from compartment to compartment during each discharge cycle. As the resin in each individual compartment absorbs the uranium from the solution passing through that compartment, the density of the resin beads increases, causing less bed expansion in that compartment. This decrease in bed expansion coupled with the transfer of equal numbers of resin beads gives rise to 
empty space above the resin in the compartments below the top compartment. Solution density changes are considered negligible ( 0.15 -percent maximum).

The spacing as a function of stage number is shown in figure 12 for various solution flow rates. Increasing the solution flow rate extends the absorption zone of the column. In other words, for a flow rate of $7.5 \mathrm{gpm} / \mathrm{ft}^{2}$, as shown in figure 9, the loading is complete in the first 8 or 9 feet of the column, and the density change occurs in those compartments. Above those compartments, no uranium is available to be loaded; therefore, no density changes take place. In contrast, at a flow rate of $12.5 \mathrm{gpm} / \mathrm{ft}^{3}$, loading occurs principal1y in the upper part of the column and, therefore, most of the density change also occurs in the upper compartments.

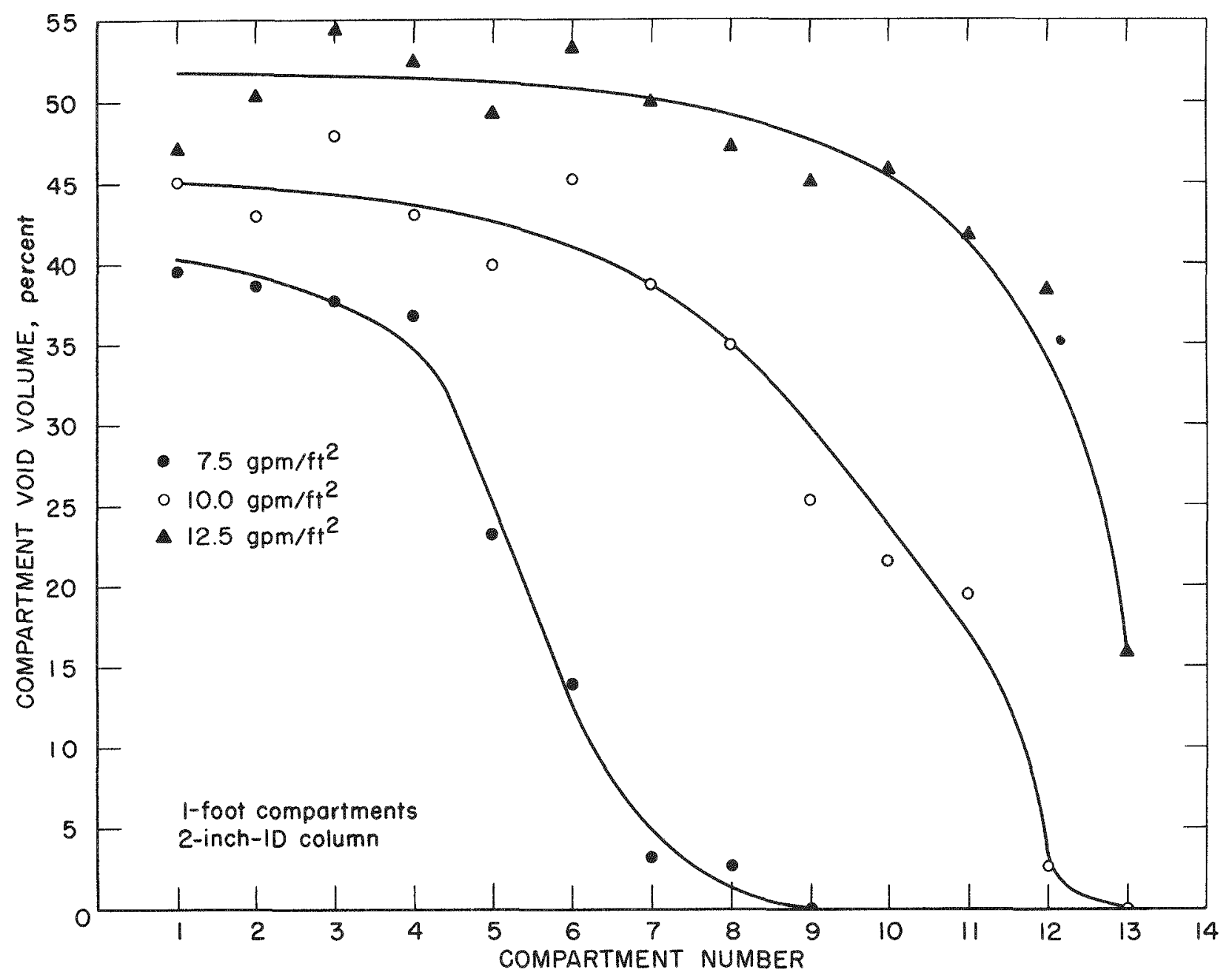

FIGURE 12. - Effect of solution flow rate on the space above the resin bed. 


\section{ELUTION COLUMN TESTS}

Operating characteristics of the countercurrent elution column were determined using Amberlite IRA 430 resin with 1.5-M NaC1 solution acidified to $\mathrm{pH} 1.0$ with $\mathrm{H}_{2} \mathrm{SO}_{4}$ as the eluant. In the integrated tests, loaded resin was obtained from the absorption column; for the individual tests, the resin was loaded to approximately 60 grams $\mathrm{U}_{3} \mathrm{O}_{8}$ per liter of wet settled resin (WSR) at a Wyoming uranium mi11. The orifice plates were perforated with one center hole per plate as follows for the three column:

$$
\begin{aligned}
& \text { 1-inch-ID column--5/16-inch-diameter hole } \\
& \text { 2-inch-ID column--29/64-inch-diameter hole } \\
& \text { 4-inch-ID column--15/16-inch-diameter hole }
\end{aligned}
$$

The columns were divided by these orifice plates into various equal section heights for the different tests. As with the absorption column, the columns were fitted with motorized valves actuated by electric timers to control the on-off flows of the solution and resin. Precision control of the solution flow rate was obtained with an automatic air-diaphragm valve coupled to a magnetic flowmeter control system for the 2- and 4-inch-ID columns. A head tank and rotameter controlled the solution flow to the 1-inch-ID column.

To obtain low effluent grades from the absorption circuit, a we11-eluted resin of less than 8 grams $\mathrm{U}_{3} \mathrm{O}_{8}$ per liter WSR is required.

The following characteristics of the MCIX elution column were studied: (1) reproducibility of results, (2) solution flow rate, (3) aqueous-to-resin flow ratio, (4) column diameter, and (5) section height. Both solution flow rate and aqueous-to-resin flow ratio are factors used in determining resin residence time and, therefore, a separate section discusses that parameter.

A replicate of tests was made to evaluate the reproducibility of column test runs. The replicate was run with a solution flow rate of $2.7 \mathrm{gpm} / \mathrm{ft}^{3}$ with a 10:1 aqueous-to-resin (A:R) ratio in the 2-inch-ID MCIX column with 1-foot sections. Elution percent data points are plotted against compartment number in figure 13. The two data-point curves roughly approximate each other, indicating reproducibility of results. 


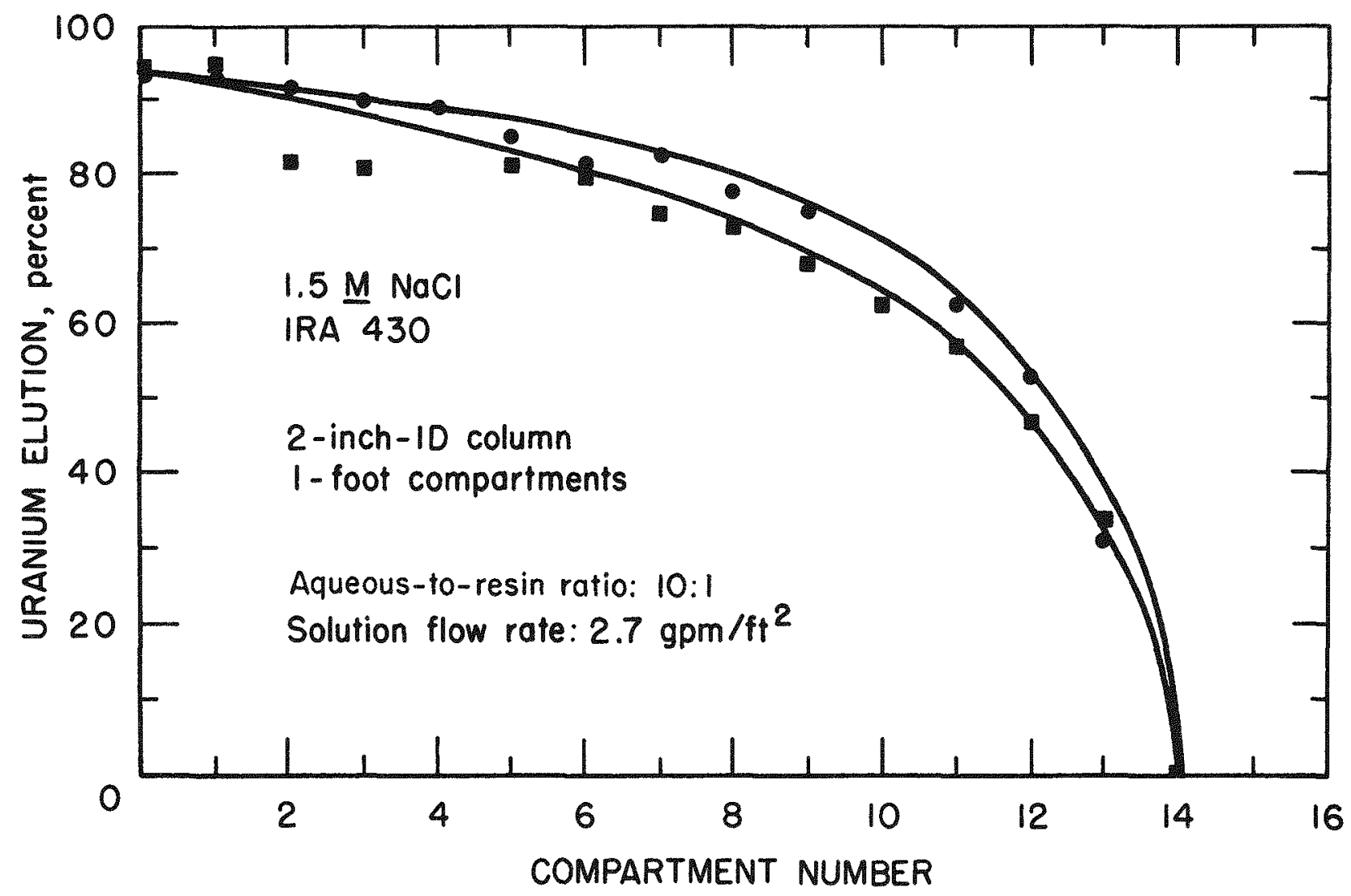

FIGURE 13. - Replication of elution column results.

\section{Resin Residence Time}

There seems to be an inverse relationship between the amount of time the resin is in contact with the eluant in the column (that is, resin residence time) and the degree of uranium elution attained. This relationship for the tests run is shown in figure 14. Resin residence time is a function of the following parameters: (1) Solution flow rate, (2) aqueous-to-resin flow ratio, and (3) column height. Table 1 shows the effect of resin residence time on the percent elution. For this series of tests, column height was held constant. A minimum of 180 to 210 minutes total resin residence time seems to be required to obtain good elution ( $<8$ grams $\mathrm{U}_{3} \mathrm{O}_{8}$ per liter of WSR). 


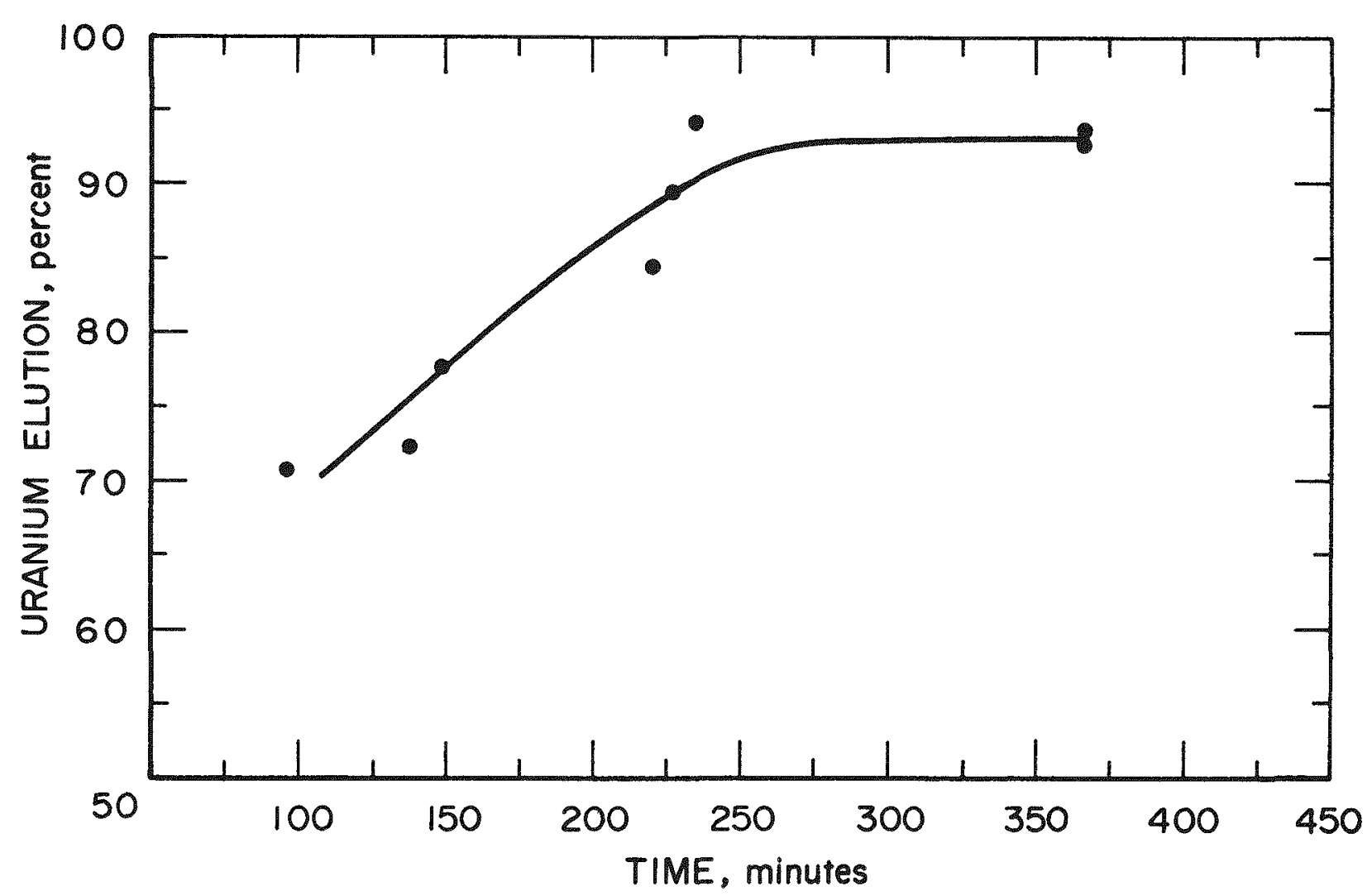

FIGURE 14: - Effect of resin residence time on elution efficiency:

TABLE 1. - Effect of resin residence time on elution

\begin{tabular}{c|c|c|c|c|c}
\hline Test & $\begin{array}{c}\text { Total resin } \\
\text { residence time in } \\
\text { column, minutes }\end{array}$ & $\begin{array}{c}\text { Resin residence } \\
\text { time per } \\
\text { compartment, } \\
\text { minutes }\end{array}$ & $\begin{array}{c}\text { Number of } \\
\text { compartments }\end{array}$ & $\begin{array}{c}\text { Entering resin } \\
\text { concentration, } \\
\text { g/1 } \mathrm{U}_{3} \mathrm{O}_{8}\end{array}$ & $\begin{array}{c}\text { Elution } \\
\text { percent }\end{array}$ \\
\hline $1 \ldots \ldots$ & 91.0 & 6.5 & 14 & 60.4 & 70.4 \\
$\ldots \ldots \ldots$ & 137.2 & 9.8 & 14 & 54.7 & 72.4 \\
$\ldots \ldots \ldots$ & 147.0 & 10.5 & 14 & 58.8 & 77.5 \\
$5 \ldots \ldots$ & 219.8 & 15.7 & 14 & 54.7 & 84.1 \\
$6 \ldots \ldots$ & 228.2 & 16.3 & 14 & 55.2 & 89.3 \\
$7 \ldots \ldots$ & 234.5 & 33.5 & 14 & 65.0 & 94.2 \\
$8 \ldots \ldots$ & 365.4 & 26.1 & 14 & 54.7 & 92.9 \\
$9 \ldots \ldots$ & 365.4 & 26.1 & 14 & 58.5 & 93.2 \\
$10 \ldots \ldots$ & 365.4 & 26.1 & 7 & 61.5 & 92.6 \\
\hline
\end{tabular}




\section{Effect of Solution Flow Rate}

The optimum economic solution flow rate per unit area of column diameter is a major consideration when designing a column system. The limiting maximum flow rate is the flow that will carry resin from the top of the column. The minimum solution flow rate to the column is determined by the resin fluidization required for efficient mechanical transfer of the resin during the withdrawal cycle. However, as the flow rate increases above this minimum, the solution residence time per foot of column height decreases, and a taller column may be required. Optimum economic design would require the optimization of the system's four parameters of column diameter, column height, solution flow rate, and resin elution.

Approximately $2.0 \mathrm{gpm} / \mathrm{ft}^{2}$ represents the minimum flow rate needed for resin transfer. Approaching this value would approximate the optimum flow that would give the maximum resin residence time for a given length of column while still being able to mechanically operate the resin withdrawal system of the column. The two eluant flow rates studied were 2.7 and $4.0 \mathrm{gpm} / \mathrm{ft}^{3}$; the results are shown in figures 15 through 18. The increase in flow rate from 2.7 to $4.0 \mathrm{gpm} / \mathrm{ft}^{3}$ reduced the resin residence time. For the tests illustrated in figures 15,16 , and 18 with an $A: R$ ratio of $10: 1$, the residence time was still sufficient to allow adequate resin elution even at the higher 4.0 $\mathrm{gpm} / \mathrm{ft}^{2}$ flow rate. In those tests, though, more column length was used for the higher flow rates. However, at the lower $A: R$ ratio of $6: 1$ illustrated in figure 17, this same increase in solution flow rate from 2.7 to $4.0 \mathrm{gpm} / \mathrm{ft}^{2}$

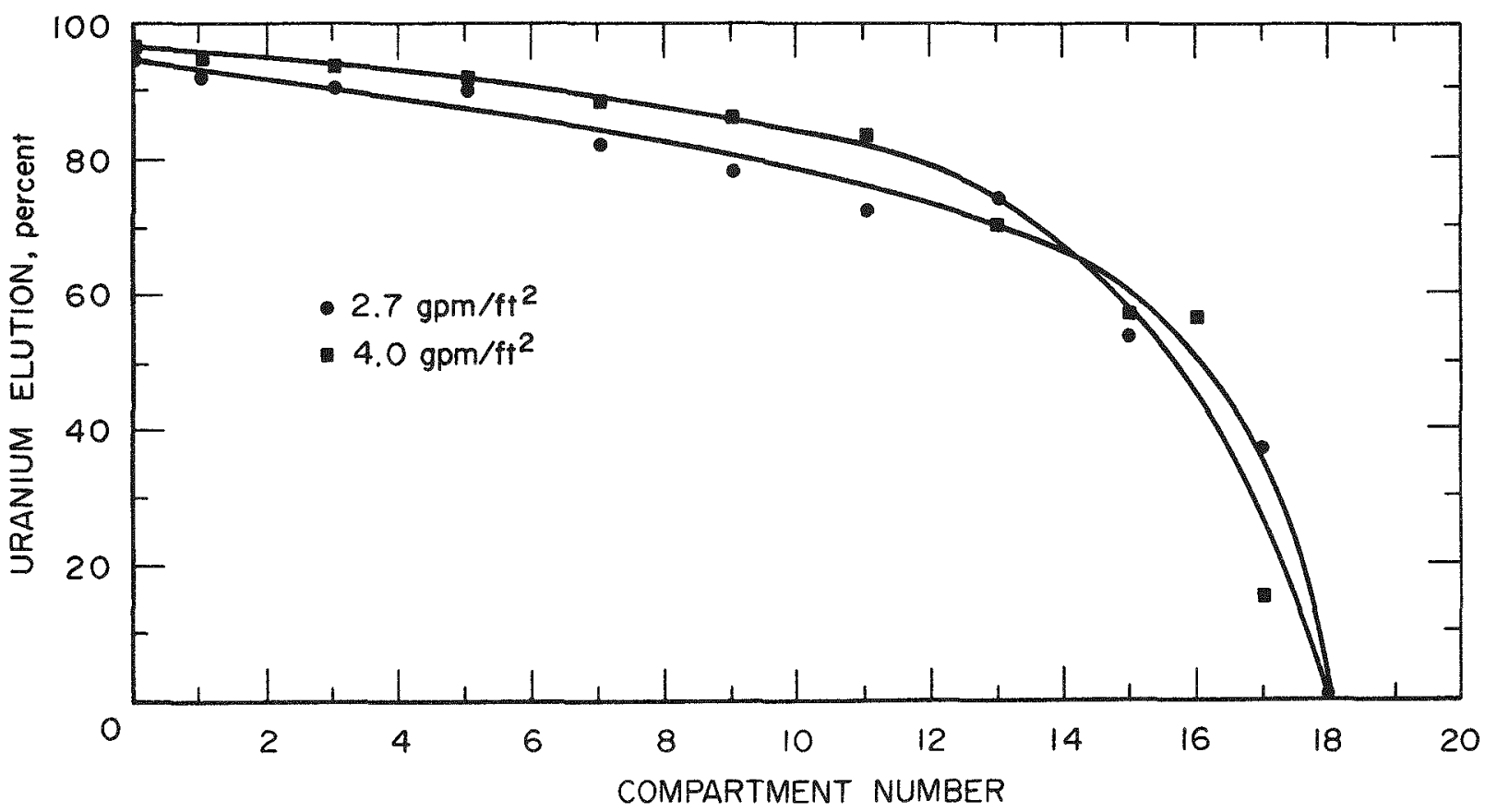

FIGURE 15. - Effect of solution flow rate on elution efficiency (1-inch-ID column, 1-foot compartments, aqueous-to-resin ratio of 10:1). 


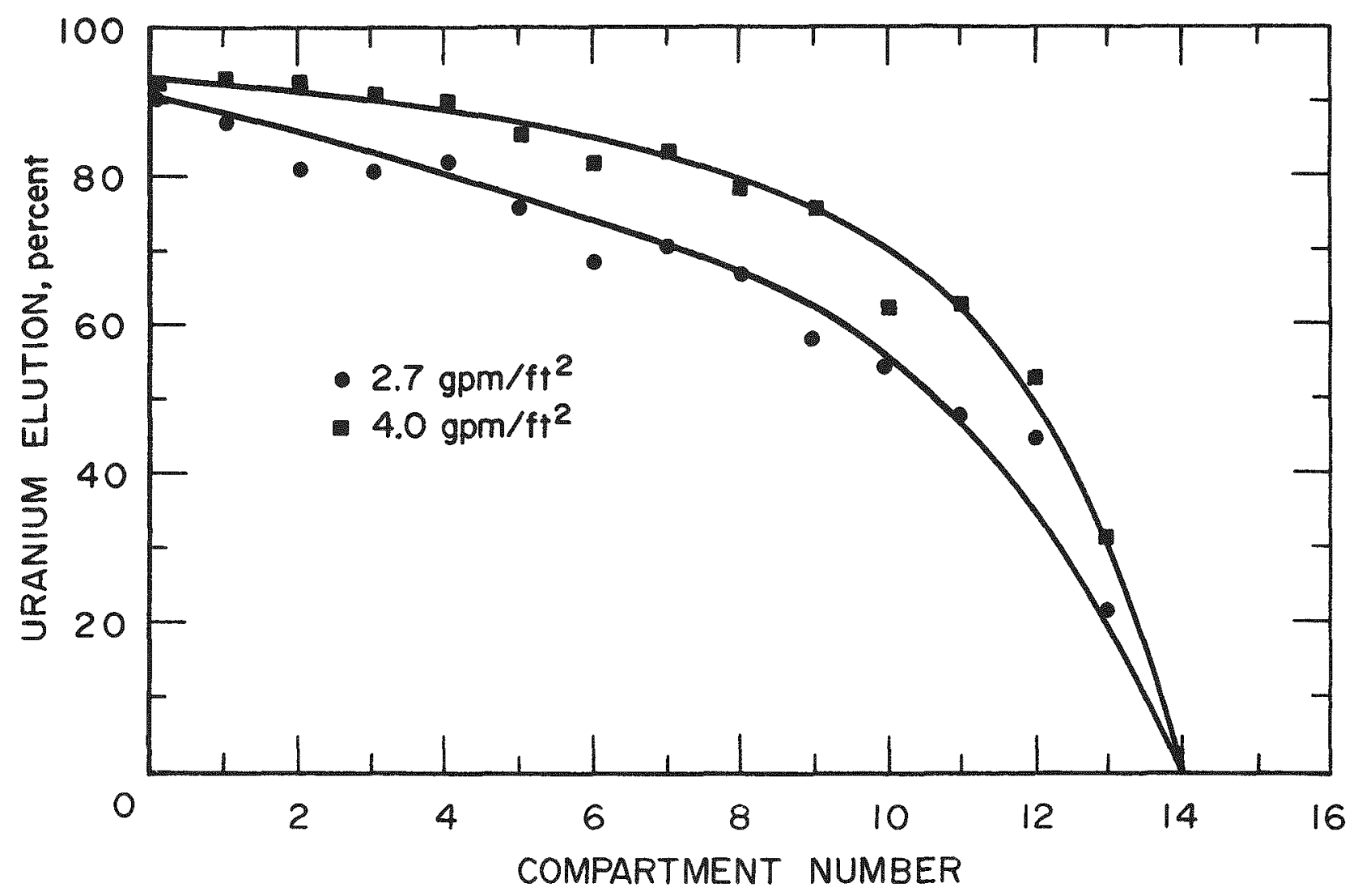

FIGURE 16. - Effect of solution flow rate on elution efficiency (2-inch-ID column, 1-foot compartments, aqueous-to-resin ratio of $10: 1 \%$.

caused a marked decrease in resin elution. For those conditions of $A: R$ and solution flow rate, the resin residence time was not sufficient. The minimum eluant flow rate of 2 to $2.7 \mathrm{gpm} / \mathrm{ft}^{2}$, which allows the maximum resin residence times, is considered optimum in order to obtain good elution of the resin and reasonable eluate grades.

\section{Effect of Aqueous-to-Resin Flow Ratio}

The $A: R$ flow ratio influences both the degree of elution and the eluate grade. There appears to be a minimum $A: R$ ratio of approximately 4:1 for good elution. This is shown by the equilibrium line (fig. 7) where a McCabeThiele operating line could not be plotted at an $A: R$ ratio of less than $4: 1$ (2). This 4:1 ratio requirement is also the result of mechanical constraints on column operation. The $A: R$ ratio would have to be optimized for each application of the column. A well-eluted resin $\left(<8 \mathrm{~g} / 1 \mathrm{U}_{3} \mathrm{O}_{8}\right)$ is required to obtain a low effluent value in the absorption circuit, but a high-grade eluate (10 to $25 \mathrm{~g} / 1 \mathrm{U}_{3} \mathrm{O}_{8}$ ) is desirable for subsequent uranium precipitation. 


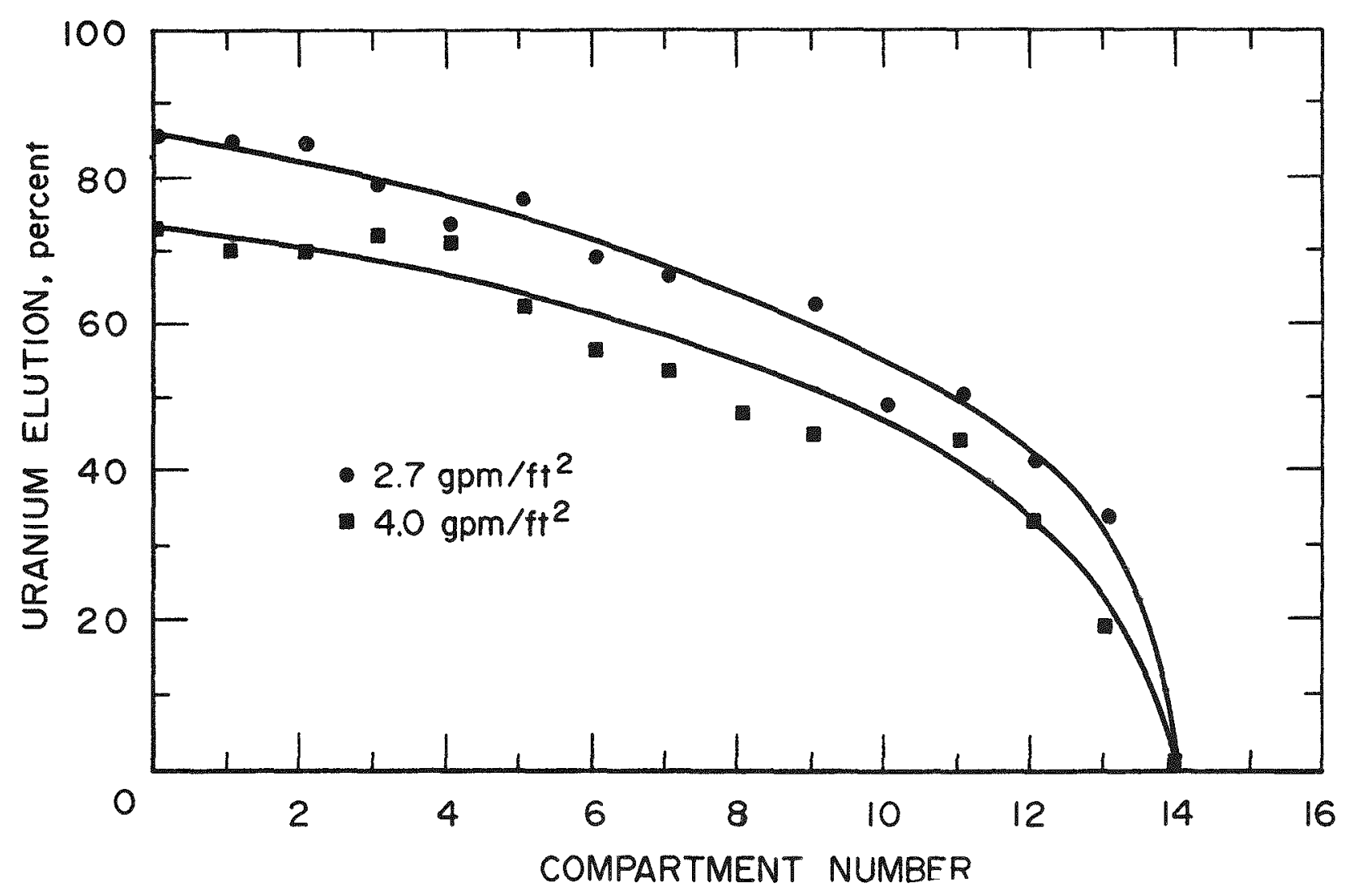

FIGURE 17: - Effect of solution flow rate on elution efficiency (2 -inch-ID column, l-foot compartments, aqueous-to-resin ratio of $6: 1)$.

For the present series of tests, the effect of $A: R$ was directly related to resin residence time. To obtain a high-grade eluate $\left(10 \mathrm{~g} / 1 \mathrm{U}_{3} \mathrm{O}_{8}\right)$, the $\mathrm{A}: \mathrm{R}$ ratio would have to be $6: 1$ or less for an entering resin concentration of approximately 50 to $60 \mathrm{~g} / 1 \mathrm{U}_{3} \mathrm{O}_{8}$. With the mechanical constraints on the minimum solution flow rate already mentioned, the desired $A: R$ ratio limits the final uranium concentration on the resin at the column height tested. With a taller column, sufficient resin residence time wolld be obtained with the minimum solution flow rate and an $A: R$ ratio in the range of $4: 1$ to $6: 1$. 


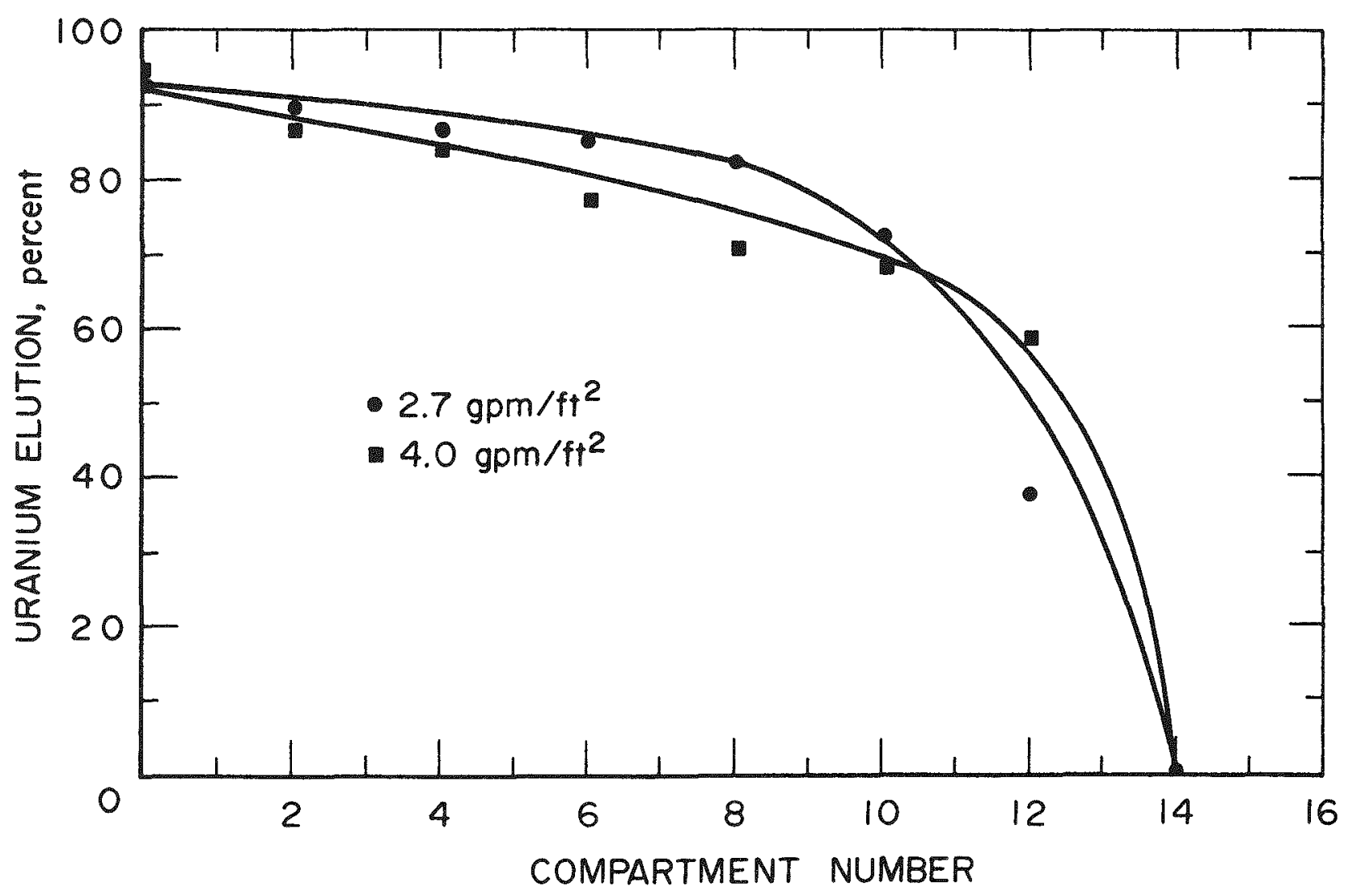

FIGURE 18: - Effect of solution flow rate on elution efficiency (2-inch-ID column, 2-foot compartments, aqueous-to-resin ratio of 10:1\%。

The effect of the $A: R$ ratio for different conditions is shown in figures 19 through 22. Large decreases in elution performance were noted with decreasing $A: R$ ratio for tests where the resin residence time was near the critical area (180 to 210 minutes), as in figures 20 and 21 . However, only slight decreases were seen with a decreased $A: R$ flow ratio when sufficient resin residence time was allowed, as was the case for those tests shown in figures 19 and 22 . 


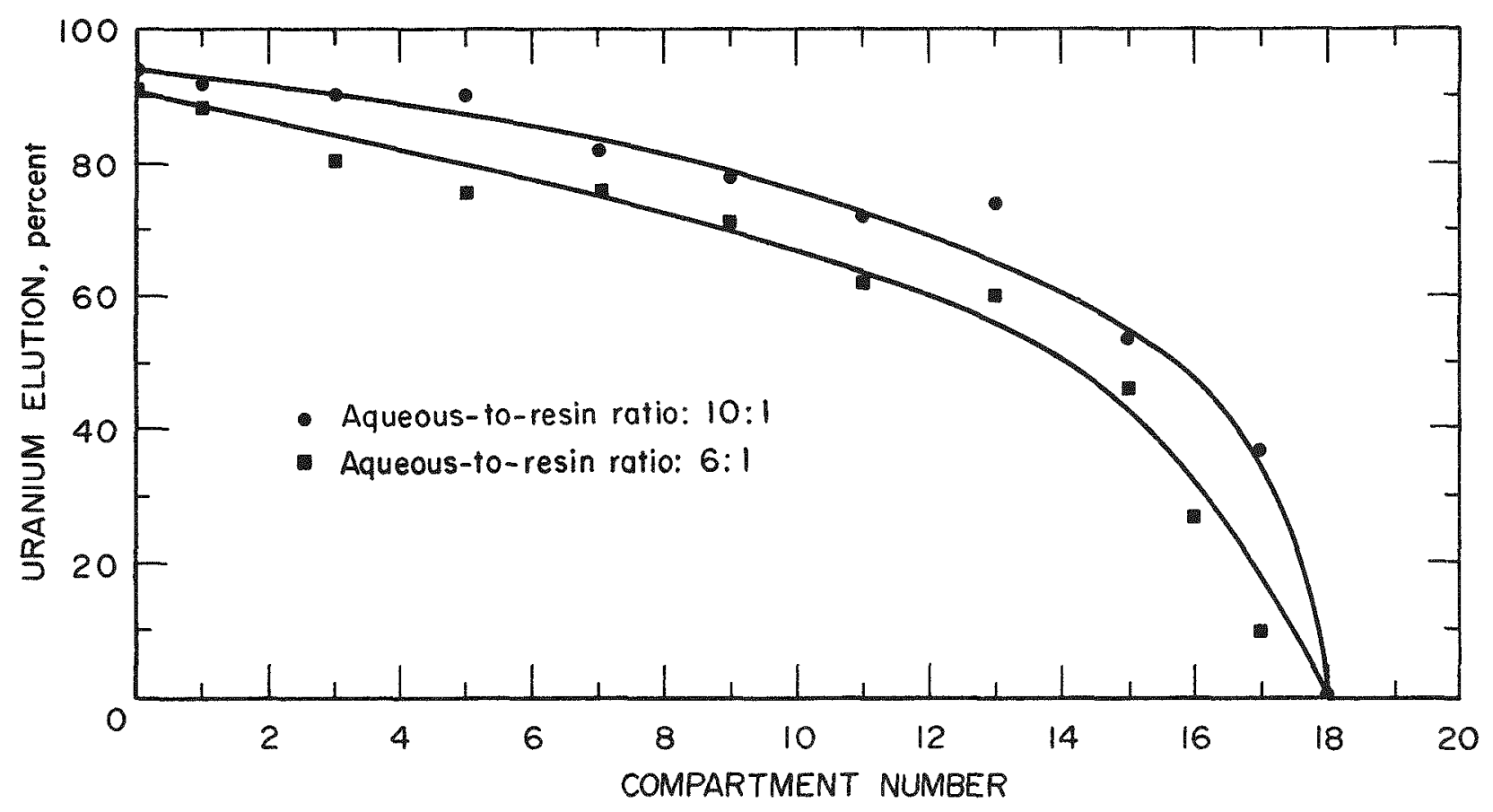

FIGURE 19. - Effect of aqueous-to-res in flow ratio on elution efficiency (1-inch-ID column, l-foot compartments, solution flow rate of $2.7 \mathrm{gpm} / \mathrm{ft}^{2}$ ).

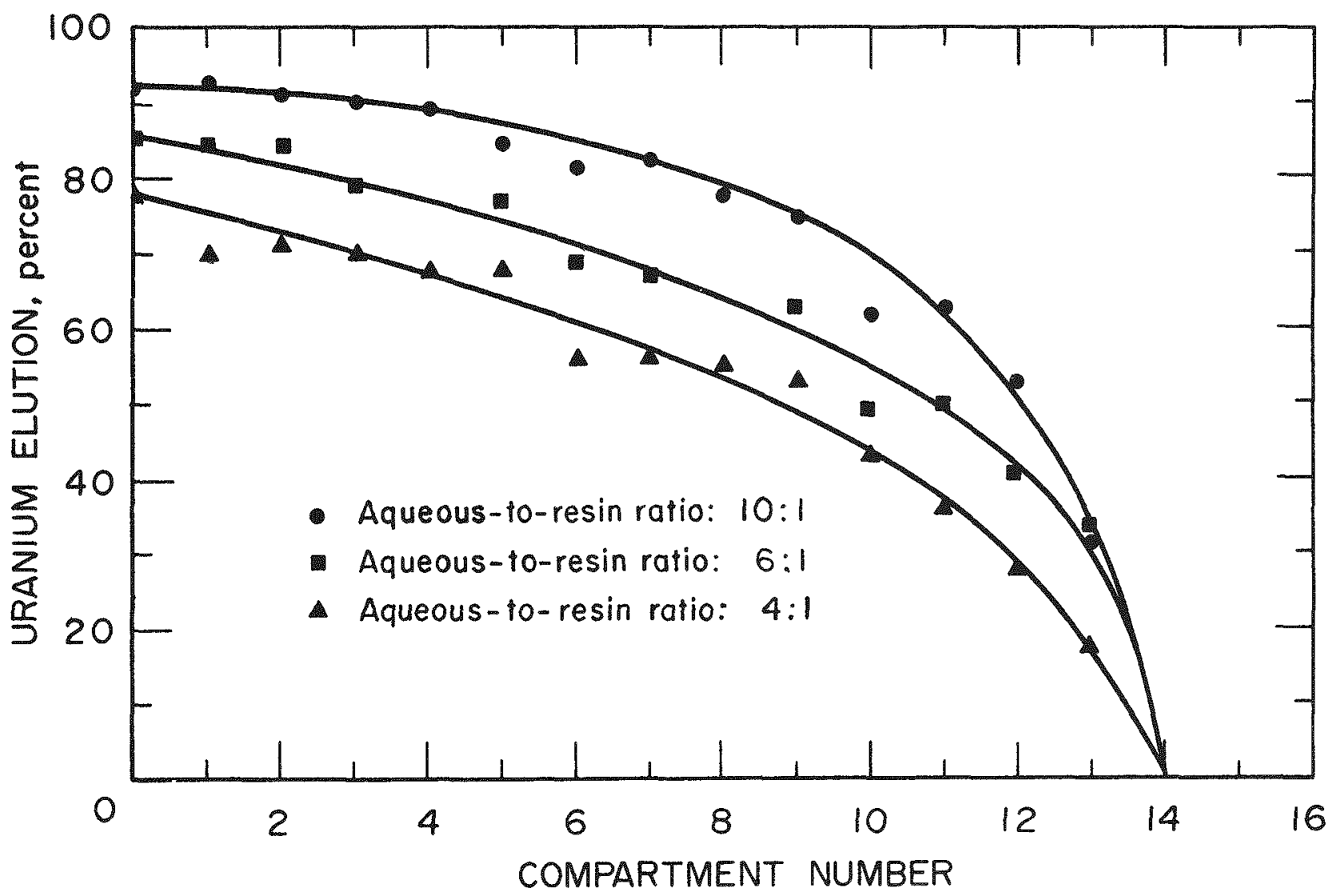

FIGURE 20. - Effect of aqueous-to-res in flow ratio on elution efficiency (2-inch-ID column, 1. foot compartments, solution flow rate of $\left.2.7 \mathrm{gpm} / \mathrm{ft}^{2}\right)$. 


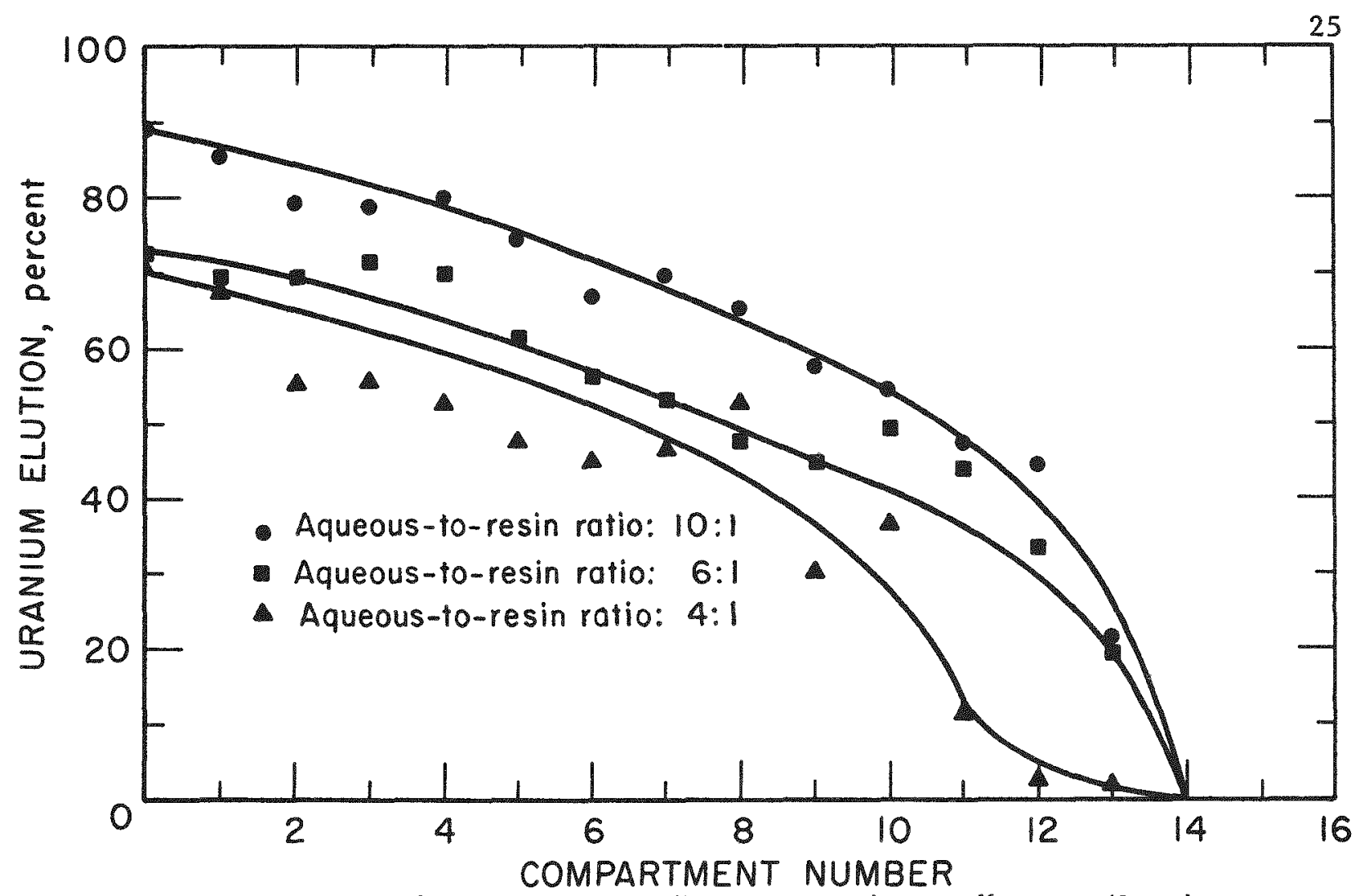

FIGURE 21. - Effect of aqueous-to-resin flow ratio on elution efficiency (2-inch-ID

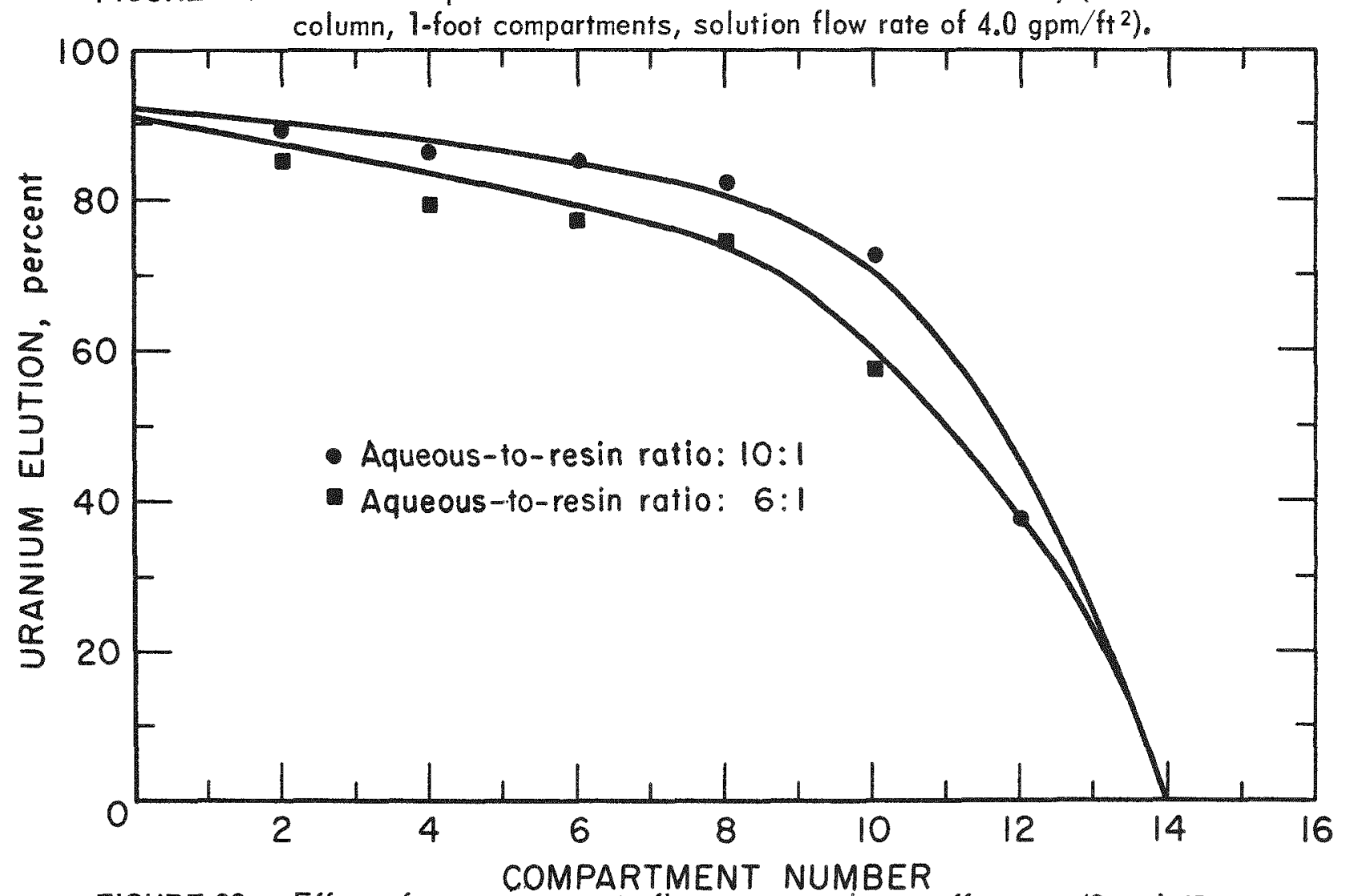

FIGURE 22. - Effect of aqueous-to-resin flow ratio on elution efficiency (2-inch-ID column, 2 -foot compartments, solution flow rate of $\left.2.7 \mathrm{gpm} / \mathrm{ft}^{2}\right)$. 


\section{Effect of Column Diametex}

Column diameter is determined by the solution flow rate, $A: R$ ratio, and the amount of resin to be processed. The wall effect that might hinder mixing in the smaller diameter columns and change elution characteristics was studied during these tests. Tests were run using 1-, 2-, and 4-inch-ID columns. The results plotted in figure 23 show no difference in elution at the bottom of the column between the three columns. However, no explanation has been deve1oped for the difference between the 2-inch-ID column results and the 1 - and 4-inch-ID column results for the upper part of the column (fig. 23).

\section{Effect of Compartment Height}

Separation of the column into stages is critically important in the elution column. Contrary to the absorption cycle in which the density changes are favorable, the reverse is true in the elution circuit. Loaded resin, which is the highest density resin, is transferced from the bottom of the absorption column to the top of the elution column. As the resin moves down through this column, it is eluted and its density decreases, thereby increas ing its bed expansion. This bed expansion would cause the lighter resin beads to be pushed into the next higher compartment, which contains denser resin beads. This trend would continue, and the top-to-bottom mixing (heavy loaded beads to the bottom and eluted beads to the top) that occurs would be

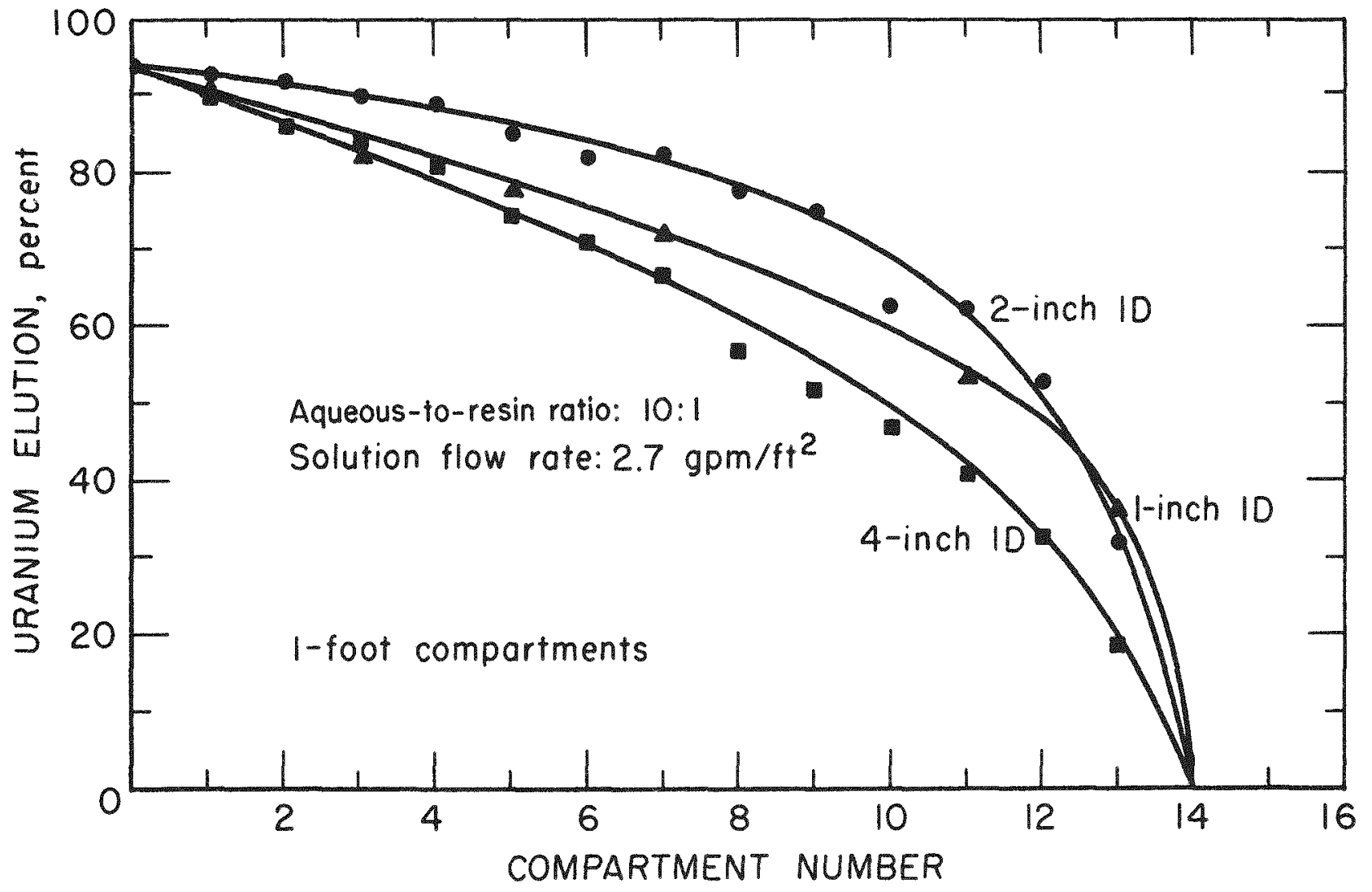

FIGURE 23. - Effect of column diameter on elution efficiency. 
detrimental to the elution operation. The density change of the solution is considered to be negligible (2.8-percent maximum). Also, exact full resin withdrawals would be very important in elution. Fractional resin withdrawals would continually draw out the heavy or more loaded resin in the bottom compartment, leaving more eluted resin in the column.

As shown in figure 24, changing the section height from 1 foot to 2 feet seems to have negligible effect on elution at $2.7 \mathrm{gpm} / \mathrm{ft}^{2}$ and an aqueous-toresin ratio of $10: 1$. Sixteen-foot-high columns with either 7 or 14 sections seem to provide enough stages to elute the resin properly at those conditions. However, with fewer stages than seven (longer lengths), proper elution might not be possible due to the previously mentioned mixing in larger diameter columns.

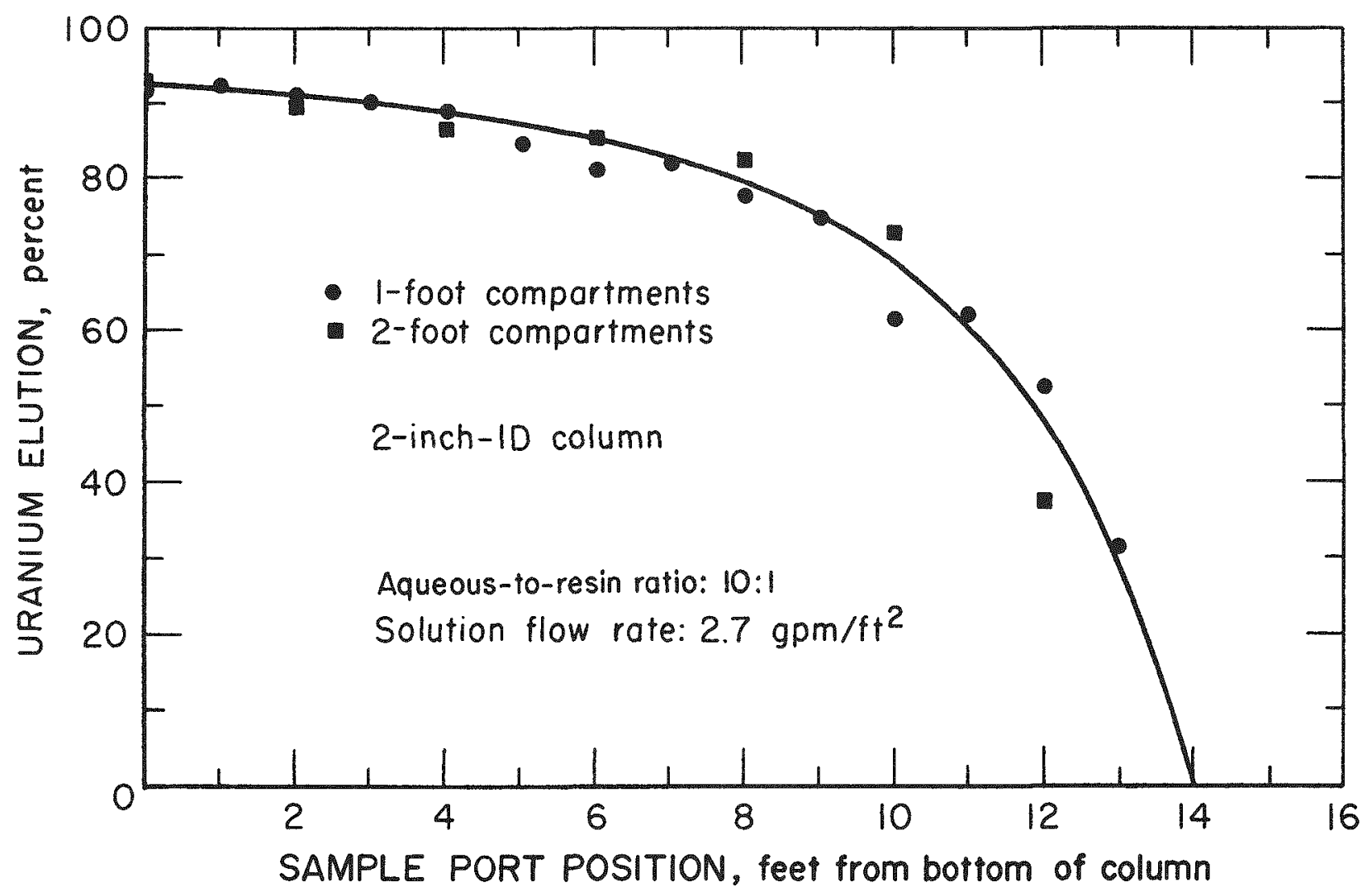

FIGURE 24. - Effect of compartment height on elution efficiency. 


\section{SUMMARY}

This phase of the design investigations on the multiple-compartment, integrated, ion-exchange columns has provided a range of operating parameters for the system. For the absorption circuit with a 16-foot-tall column and 1- or 2-foot-high compartments, a solution flow rate of $10 \mathrm{gpm} / \mathrm{ft}^{2}$ was optimum. The solution retention time in the column, which is a function of solution flow rate, was the controlling factor for uranium absorption. When feed solutions of $1 \mathrm{~g} / 1 \mathrm{U}_{3} \mathrm{O}_{8}$ were used, the uranium loading on the resin was about $55 \mathrm{~g} / 1 \mathrm{U}_{3} \mathrm{O}_{8}$.

In the elution circuit, a solution flow rate of $2.7 \mathrm{gpm} / \mathrm{ft} \mathrm{t}^{2}$ with an $\mathrm{A}: \mathrm{R}$ of 4:1 in a column with fourteen 1-foot sections provided an eluate grade of $12 \mathrm{~g} / 1 \mathrm{U}_{3} \mathrm{O}_{8}$ with an exiting eluted resin of $7 \mathrm{~g} / 1 \mathrm{U}_{3} \mathrm{O}_{8}$. The resin residence time as controlled by solution flow rate and $A: R$ ratio was the determining factor in uranium elution efficiency. To obtain an eluted resin of $8 \mathrm{~g} / 1$ $\mathrm{U}_{3} \mathrm{O}_{8}$, a resin residence time in excess of approximately 180 to 210 minutes is required. Obtaining higher grades of eluate and/or lower exiting resin values would require a taller column to provide longer resin residence time. 


\section{REFERENCES}

1. George, D. R., J.R. Ross, and J. D. Prater. Byproduct Uranium Recovered With New Ion-Exchange Techniques. Min. Eng., v. 20, January 1968, pp. 1-5.

2. McCabe, W. L., and J. C. Smith. Unit Operations in Chemical Engineering. McGraw-Hi11 Book Co., Inc., New York, 2d ed., 1967, pp. 526-530.

3. Merritt, R. C. The Extractive Metallurgy of Uranium. Colorado School of Mines Research Institute, Golden, Colo. (under contract with the U.S. Atomic Energy Commission), 1971, 576 pp.

4. Pizarro, R., J. D. McBeth, and G. M. Potter. Heap Leaching Practice at the Carlin Gold Mining Co., Carlin, Nev. Solution Min. Symp., Dallas, Tex. Feb. 25-27, 1974. American Institute of Mining, Metallurgical, and Petroleum Engineers, Inc., New York, 1974, pp. 253-267.

5. Rosenbaum, J. B., and D. R. George. Cost Reductions in Ion-Exchange Processing of Uranium Ores--the Recovery of Uranium. Proc. IAEA Symp., Sqo Paulo, Brazil, Aug. 17-21, 1970. International Atomic Energy Agency, Vienna, Austria, 1970, pp. 297-309.

6. Rosenbaum, J. B., and J.R. Ross. A Countercurrent Column for Fluid-Bed Ion Exchange of Uranium Ore Slurries. Internat. Symp. on Hydrometallurgy, Chicago, I11., Feb. 25-Mar. 1, 1973. American Institute of Mining, Metallurgical, and Petroleum Engineers, Inc., New York, 1973, pp. 535-551.

7. Ross, J.R., and D. R. George. Recovery of Uranium From Natural Mine Waters by Countercurrent Ion Exchange. BuMines RI 7471, 1971, 17 pp .

8. Treybal, R. E. Liquid Extraction. McGraw-Hill Book Co., Inc., New York, 2d ed., 1963, pp. 361-368. 